\title{
3. Maßnahmen gegen die Republikfiucht 1952-1961: Die Wirkungslosigkeit von Zuckerbrot und Peitsche
}

Die SBZ bzw. DDR zählte bis 1961 niemals mehr als 19 Millionen Einwohner. ${ }^{1}$ Innerhalb von sechzehn Jahren gingen etwa drei Millionen davon nach Westdeutschland. Seit 1951 waren dies nur in einem Jahr erheblich weniger als ein Prozent der Bevōlkerung. ${ }^{2}$ Die Auswanderung war somit ein chronisches Problem des ostdeutschen Staates; die deutschen und sowjetischen Kommunisten bauten eine Gesellschaftsordnung auf, die von groBen Teilen der Bevölkerung nicht akzeptiert wurde. Daher war die Bereitschaft, die Heimat zu verlassen und Zuflucht im westlichen Teil Deutschlands zu suchen, stark ausgeprägt. Angesichts ihres Umfangs und ihrer Kontinuitāt erscheinen die strukturellen Ursachen und Gründe für die Fluchtbewegung wichtiger als die zu bestimmten Zeiten akuten, zumeist durch politische MaBnahmen hervorgerufenen.

Diese Ausgangslage und der recht kurze Untersuchungszeitraum von 16 Jahren relativieren die Bedeutung von chronologischen Einschnitten und der Auswirkung von einzelnen politischen Aktionen und Ereignissen. Im folgenden wird die Fluchtbewegung daher nach einer Skizze der von Ost-Berlin gesetzten juristischen Rahmenbedingungen chronologisch anhand von drei großen zeitlichen Einschnitten dargestellt. Anschließend zeigen die zahlreichen größeren und kleineren Initiativen, die Regierung und SED im Laufe der fünfziger Jahre erließen, daß sie keine systematische politische Linie gegen die Republikflucht verfolgten und damit vor allen Dingen nicht die intendierte Wirkung erzielten.

\subsection{Juristische Rahmenbedingungen}

Die Verfassung der DDR vom 7. Oktober 1949 hatte im Artikel 8 die Bestimmung der Weimarer Verfassung übernommen, nach der sich jeder Bürger an einem beliebigen Ort niederlassen kōnne und im Artikel 10 darüber hinaus festgelegt: $\sqrt{ }$ Jeder Bürger ist berechtigt auszuwandern. "3 Freizügigkeit war den DDR-Bürgern laut Verfassung demnach auch über die Landesgrenzen hinaus garantiert. In den folgenden Jahren erließ die DDR-Regierung jedoch zahlreiche Gesetze, die das ursprünglich garantierte Recht auf Auswanderung nach und nach einschränkten; DDR-Bürger, die das Land verlassen wollten, wurden auf diese Weise kriminalisiert.

\footnotetext{
' Statistisches Jahrbuch der DDR 1961, S. 17.

21959 verließen etwa 145000 Personen, also ungefāhr 0,8 Prozent der Bevölkerung das Land. Angabe nach der Schätzung der Zentralverwaltung (ZV) für Statistik der DDR (vgl. Tabelle 1). Dies ist die niedrigste verfügbare Zahl. Die Angaben der polizeilichen Meldestellen der DDR und vor allem der westlichen Institutionen liegen noch erheblich hōher. Zu letzteren vgl. Heidemeyer, Flucht und Zuwanderung (1994), S. 37-48.

${ }^{3}$ Zitiert nach: Handbuch der Volkskammer (1959), S. 13-68, hier S. 33. In Artikel 1 hieB es überdies: „Es gibt nur eine deutsche Staatsangehörigkeit.“ Ebd., S. 31.
} 
Das erste Gesetz, das eine Strafandrohung für ein nicht genehmigtes Überschreiten der Grenze zwischen DDR und Bundesrepublik enthielt, war die „Verordnung über die Rückgabe Deutscher Personalausweise“ vom 25.1.1951.4 In ihr wurde verfügt, daß vor einer Übersiedlung nach Westdeutschland oder West-Berlin der Personalausweis abzugeben sei. Zuwiderhandlungen wurden mit Geldstrafe oder Gefängnis bis zu drei Monaten bestraft. ${ }^{5}$ Diente diese Verordnung ursprünglich dem Bestreben, den Grenzverkehr zwischen Ost und West zu kontrollieren, wurde mit Hilfe des Paragraphen bald auch die Flucht in den Westen - über den Umweg des nicht rechtmäßig abgelieferten Personalausweises - sanktioniert. Aus dieser Anwendung der Verordnung machten die Behörden intern auch keinen Hehl: So formulierte eine Denkschrift der Volkspolizei vom September 1955 ausdrũcklich, daB die Bestrafung der Republikflucht mangels eines eigenen Gesetzes indirekt geschehen solle, am einfachsten wegen des nicht abgegebenen Personalausweises: „Tatsache ist jedoch, daB die Anwendung dieser Strafe nicht deshalb geschieht, weil Bürger ihren PA [Personalausweis] mitnehmen, sondern um der Republikflucht entgegenzuwirken." 6

Dieses Verfahren ist kennzeichnend für den juristischen Umgang mit der Republikflucht. Weil sie bis Ende 1957 keinen eigenen Straftatbestand darstellte, wurden die betroffenen Personen mittels anderer Gesetze strafrechtlich verfolgt. Schon eine Rundverfügung des Justizministers und des Generalstaatsanwalts der DDR vom September 1950 enthielt Hinweise, wie ungenehmigte Grenzüberschreitungen auch ohne formale strafrechtliche Norm bestraft werden konnten, etwa nach wirtschafts- oder preisstrafrechtichen Bestimmungen.7 Am 31. Januar 1953 teilte der stellvertretende Chef der Volkspolizei, Seifert, seinen Bezirksbehörden mit, daß gegen alle bei versuchter Republikflucht festgenommenen Männer Haftbefehl zu erwirken sei. Unverblümt verlangte er Untersuchungen, um sie wegen krimineller Delikte anklagen zu können, und machte dazu konkrete Vorschläge: „Verbrechen gegen die Wirtschaftsstrafverordnung, Steuerhinterziehung, Verstoß gegen das Gesetz zum Schutz des Innerdeutschen Zahlungsverkehrs, illegaler Waffenbesitz (soweit durch Haussuchungen nachgewiesen) usw. ${ }^{48}$

Erst mit dem „Gesetz zur Änderung des Paßgesetzes der DDR“ vom 11. Dezember 1957 wurde die nicht genehmigte Überschreitung der Westgrenze der DDR in $\S 8$ zu einem selbstāndigen Tatbestand. ${ }^{9}$ Damit kam die DDR-Regierung einer bereits seit längerem erhobenen

\footnotetext{
4 Vgl. Dok. 1 .

${ }^{5}$ Bereits Ende 1953 wurde das Strafmaß für den gleichen Tatbestand auf eine Gefängnisstrafe von „bis zu drei Jahren“" erhōht. Vgl. Dok. 6. Zuvor, im Juli 1952, war bereits verfügt worden, das Vermōgen von Personen, die das Gebiet der DDR verlassen, „ohne die polizeilichen Meldevorschriften zu beachten, oder hierzu Vorbereitungen treffen, zu beschlagnahmen." Vgl. Dok. 3. Im Zuge des „Neuen Kurses“" wurde diese Bestimmung wieder aufgehoben. Vgl. Dok. 5.

${ }^{6}$ Denkschrift der HVDVP, HA PM, 28.9. 1955, BArch DO 1/11, Nr. 963, BI. 39-43, hier Bl. 42.

7 Rundverfügung Nr. 126/50 vom 26. September 1950, zitiert nach Bundesministerium für innerdeutsche Beziehungen, DDR-Handbuch (1979), S. 909. Anhand der - noch auf die NS-Zeit zurückgehenden - Paßstrafverordnung konnten die Vergehen laut der Verfügung nicht geahndet werden, weil diese eine Staatsgrenze voraussetzte, als die die Demarkationslinie offenbar noch nicht angesehen wurde.

${ }^{8}$ BArch DO 1/11, Nr. 962, Bl. 10, 13. Müttern und Kindern sollten die Personalausweise abgenommen werden, und sie sollten mit einer vorläufigen PM 12a an ihren Wohnort geschickt werden. Dort sollten die 30 Tage gültigen PM 12a fünfmal für jeweils einen Monat verlāngert werden, so daß Personen nach ihrem gescheiterten Versuch einer Republikflucht ein halbes Jahr ohne eigenen Personalausweis und in ständigem Kontakt mit der VP lebten.

9 Dok. 8.
} 
Forderung aus den Reihen der HVDVP nach. ${ }^{10}$ Das Gesetz enthielt zwar nur minimale sprachliche Korrekturen gegenūber dem alten Gesetzestext vom 15. September $1954^{11}$, diese hatten aber zur Folge, daB der nicht genehmigte Umzug nach Westdeutschland nun einen selbständigen Straftatbestand darstellte, der mit einer bis zu dreijāhrigen Gefangnisoder Geldstrafe geahndet wurde. Darüber hinaus wurde im Gegensatz zum Gesetz von 1954 bereits die Vorbereitung einer Flucht kriminalisiert. Auf diese Weise wurden der ohnehin schon willkürlichen Ahndung der unerlaubten Grenzübertritte noch weitere Türen geöffnet.

Mit dem Paßānderungsgesetz setzte ein schärferes Vorgehen gegen Auswanderungswillige und illegale Grenzūbertritte ein: Allein in den ersten beiden Monaten nach ErlaB des PaBãnderungsgesetzes am 11. Dezember 1957 wurden 1095 Ermittlungsverfahren und 340 Festnahmen wegen des verschärften Republikfluchtparagraphen 8 angestrengt, von denen 854 Ermittlungsverfahren und 223 Festnahmen angebliche Vorbereitungen und Versuche zur Republikflucht betrafen. ${ }^{12}$ Anfang April 1958 waren 1681 Personen nach dem neuen Gesetz bestraft worden, wobei es sich nicht bei allen Fällen um versuchte Republikfluchten gehandelt haben muB, da das Gesetz auch Fristüberschreitungen bei der Aus- und Rückgabe der seit Ende Oktober 1953 für alle Reiseangelegenheiten zentralen PaB- und Meldebescheinigung (PM) 12a bestrafen lieB. ${ }^{13}$ Das Gesetz und seine Anwendung zeigten den politischen Willen Ost-Berlins, den gesamten grenzüberschreitenden Verkehr stärker zu kontrollieren und einzuschränken. So zogen die Polizeiämter auch wieder viele Personalausweise von Fluchtverdãchtigen ein, obwohl die HVDVP dies erst am 26. Juni 1956 untersagt hatte. ${ }^{14}$ Schon im Vorfeld der Gesetzesreform wurden zunehmend weniger Reisen in den Westen erlaubt: ${ }^{15}$ Während im ersten Quartal 1957 nur 0,1 Prozent aller diesbezüglichen Anträge abgelehnt wurden, waren es im vierten Quartal 27,7 Prozent und im Dezember 1957 sogar 38,9 Prozent. ${ }^{16}$

\subsection{Maßnahmen zur Beklimpfung der Republikfiucht im Rahmen des "Neuen Kurs"}

Im Zuge der politischen Verschärfungen seit 1952 nahmen die Flucht aus der DDR und die Wahrnehmung der damit für die ostdeutsche Gesellschaft verbundenen Probleme

${ }^{10}$ BArch DO 1/11, Nr. 963, Bl. 39-43. Auch in der Staatichen Plankommission war bereits am 28. 2. 1957 erwogen worden, das Recht auf Abwanderung aus der DDR, welches aus dem Recht auf Auswanderung (Verfassung Artikel 10) abgeleitet wird, gesetzlich zu beschränken" (BArch DE 1, Nr. 6109, Bl. 2 f.).

$1 \mathrm{GBl}$. Nr. 81, 22. 9. 1954, S. 786. Die entscheidende Veränderung bestand darin, daß 1954 nur das unerlaubte Verlassen der DDR "nach dem Ausland“ untersagt worden war. Weil in der Version vom 11.12. 1957 das Ausland nicht mehr erwähnt wurde, war nun auch der Fortgang in die Bundesrepublik strafbar. Die einzige Entschärfung bestand darin, daß neben der Gefängnisstrafe nun auch Geldstrafen verhängt werden konnten.

12 BArch DO 1/11, Nr. 780, Bl. 32-40, hier Bl. 32.

is BArch DO 1/11, Nr. 965, Bl. $49 \mathrm{f}$.

is HA PM am 28.7. 1958 über 3952 eingezogene Personalausweise, BArch DO 1/11, Nr. 965, Bl. 67; BArch DO 1/11, Nr. 963, Bl. 195.

is Seit dem 1.10. 1956 wurden Anträge auf Übersiedlung nach Westen nicht mehr von den Volkspolizeikreisämtern, sondern von den Abt. IA bei den Rāten der Kreise bearbeitet (BArch DO 1/11, Nr.963, Bl. 206, 218).

16 Verschärfend kam hinzu, daß ab dem 1.1.1958 angeblich zum Besuch von Republikflüchtigen keine Reisegenehmigungen mehr erteilt wurden. (Ratsvorlage vom 4.6.1958 in Karl-Marx-Stadt, 
stark zu. Die bereits für 1952 festgestellte Initiativfunktion der sowjetischen Besatzungsmacht bei der kritischen Beobachtung der unkontrollierten Auswanderung trat ein Jahr später wieder in Erscheinung, als die SED - zu spāt - versuchte, sich in geordneten Bahnen von ihrem radikalisierten Weg zum Sozialismus zurückzuziehen. Wiederum hatte Karlshorst die steigenden Fluchtzahlen wahrgenommen; die Kritik der sowjetischen Führung vom 2. und 3. Juni 1953 am verschärften Kurs zum Sozialismus bezog sich auch auf die Fluchtbewegung, die als Indiz für eine falsche Politik erkannt wurde: In der DDR sei

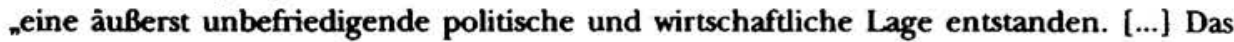
kommt am deutlichsten in der massenhaften Flucht der Einwohner der DDR nach Westdeutschland zum Ausdruck. ${ }^{\text {"17 }}$ In Abhängigkeit von Moskau zeigten sich die deutschen Kommunisten gezwungenermaßen lernfähig: Am 9. Juni 1953 beschloß das Politbüro auf Anordnung Moskaus den Neuen Kurs und beschrieb den bislang eingeschlagenen Weg durchaus selbstkritisch: "Eine Folge war, daB zahlreiche Personen die Republik verlassen haben ${ }^{4} .^{18}$ Der Ministerratsbeschluß vom 11. Juni $1953^{19}$ ergānzte den Reformkurs; Gesetze und Maßnahmen, die einzelne Berufs- und Bevölkerungsgruppen drangsaliert hatten, wurden zurückgenommen. So korrigierte die Regierung ihre bauernfeindliche Politik, indem sie die Verordnung über devastierte landwirtschaftliche Betriebe zurücknahm und sogar versprach, einzelne Entwicklungen rückgāngig zu machen: „Die Bauern, die im Zusammenhang mit Schwierigkeiten in der Weiterführung ihrer Wirtschaft ihre Höfe verlassen haben und nach Westberlin oder nach Westdeutschland geflüchtet sind [...] sollen die Mōglichkeit erhalten, auf ihre Bauernhōfe zurückzukehren. Ist das in Ausnahmefällen nicht möglich, so sollen sie vollwertigen Ersatz erhalten. [...] Strafen, die wegen Nichterfüllung von Ablieferungsverpflichtungen oder Steuerverpflichtungen ausgesprochen wurden, sollen überprüft werden." SED und Regierung gingen noch weiter und hoben die Verordnung vom 17. Juli 1952 auf, in der verfügt worden war, den Besitz von allen illegal Ausgewanderten zu beschlagnahmen. Alle Rückkehrer sollten ihr Hab und Gut zurückerhalten und in den "Einzelfallen", bei denen eine Rückgabe nicht möglich sei, „soll Ersatz geleistet werden. Zurūckkehrenden Republikflüchtigen darf aus der Tatsache der Republikflucht keine Benachteiligung entstehen. ${ }^{{ }^{20}}$ Die berufsbezogene Statistik zeigt den Erfolg dieser Entscheidung: In der zweiten Hälfte des Jahres 1953 flohen gegen über dem ersten Halbjahr 90 Prozent weniger Bauern in den Westen. ${ }^{21}$

Auch die geflohene Intelligenz wurde gesondert angesprochen; da ihre Flucht - neben der der Bauern - der SED am meisten Sorge bereitet hatte. So wurde etwa die Möglichkeit zur Teilnahme an Tagungen im Westen erleichtert, da zahlreiche Akademiker die entspre-

BArch DO 1/34, Nr. 21727); zu den Folgen dieser Kriminalisierung vgl. BArch DO 1/11, Nr. 780. Bl. 32-40.

17 Undatierter Beschluß des ZK der KPdSU von Ende Mai 1953, in: Stōckigt, Dokument (1990), S. 651-654, hier S.651. Auch in Hoffmann/Schmidt/Skyba, Die DDR vor dem Mauerbau (1993), S. 152-158.

18 Kommuniqué des Politbüros in: Dokumente der SED, Bd. 4, S. 428-431, hier S. 428.

19 ND Nr. 135 v. 12.6. 1953, S. 1. Der Ministerrat versprach dabei Preissenkungen, die Wiedereinführung von sozialen Erleichterungen etc. und nicht zuletzt die Zusicherung an Rückkehrer, daß sie wieder in ihre alten Rechte eingesetzt würden.

${ }^{20}$ "Verordnung über die in das Gebiet der Deutschen Demokratischen Republik und den demokratischen Sektor von Berlin zurūckkehrenden Personen“ vom 11.6. 1953 (Dok. 5).

21 Vgl. Bispinck, Flucht- und Ausreisebewegung (2004), S. 155, sowie das Diagramm ebd., S. 154. 
chenden Verbote immer wieder als unzumutbare berufliche Einschrānkung kritisiert hatten. ${ }^{22}$ Auch der sonstige Reiseverkehr wurde im Zuge dieser Erleichterungen liberalisiert. So tat das Politbūro seine Auffassung kund, daB die „Aufenthaltsgenehmigungen für Westdeutsche und Westberliner sowie die Frage der Ausstellung von Interzonenpässen im Sinne der Erleichterung des Verkehrs zwischen Ost- und Westdeutschland neu geregelt werden" mūßten; ausdrücklich schlug es die Anerkennung "familiäre[r] Gründe" für grenzüberschreitende Reisen vor. ${ }^{23}$ Am 15. Juni 1953 wies daraufhin die HVDVP ihre nachgeordneten Polizeiämter an, fast alle Privatreisen zu gestatten. ${ }^{24}$ Die Zahl der Westreisen stieg danach sprunghaft an: Während im April und Mai 806 bzw. 853 solcher Reisen genehmigt worden waren, betrug die Zahl der ausgestellten Pässe im Juni, Juli und August 19533836,134545 bzw. 287504.25

Der ,Neue Kurs' wirkte wie eine Sensation ${ }^{26}$ und hatte einen spürbaren Rückgang der Flüchtlingszahlen zur Folge. Die Erleichterungen wurden fast überall zustimmend und mit Genugtuung aufgenommen, führten aber nicht zu weniger, sondern eher zu mehr Kritik an Ulbricht, Pieck und Grotewohl, den wichtigsten Repräsentanten von SED und Regierung. ${ }^{27}$ Entscheidend dafür war, daB zwar viele Revisionen angekündigt und angeordnet, von den Staats- und Parteiorganen vor Ort aber nur halbherzig durchgeführt wurden und daB es nicht zur Zurücknahme der im Mai verfügten Erhōhung der Arbeitsnormen kam. ${ }^{2}$ Nicht zufälig lōsten gerade Arbeiter wenige Tage spãter die Unruhen vom 17. Juni 1953 aus und bildeten deren Rückgrat. ${ }^{29}$ So ging unter den Republikflüchtigen die Zahl der Arbeiter im folgenden Jahr - im Gegensatz zu allen anderen Berufsgruppen - auch nicht zurück, sondern stieg um über sieben Prozent von 48431 (1953) auf 52145 (1954), wāhrend sich die Zahl der Bauern und Handwerker von 11613 bzw. 11744 auf 2389 bzw. 5913 drastisch verringerte. ${ }^{30}$ Neben der Rücknahme der Maßnahmen gegen selbstāndig wirtschaftende Bauern, Handwerker und Einzelhāndler sowie gegen Akademiker entspannte auch der weniger aggressive Kurs gegen die Kirchen das öffentliche Leben. Durch wirtschaftspolitische Korrekturen und nicht zuletzt durch die Übergabe der SAG-Betriebe an die DDR und eine starke Verringerung der sowjetischen Reparationsfor-

\footnotetext{
22 Kommuniqué des Politbüros, S. 430.

23 Ebd.

24 Dienstanweisung 25/58, BArch DO 1/11, Nr. 955, Bl. $39 \mathrm{f}$.

${ }^{25}$ Der sprunghafte Anstieg wurde auch in den Führungsgremien der SED angesprochen. So beschlo $B$ das Politbüro am 4. 8. 1953, die Zahl der wöchentlichen Interzonenzüge nach Hamburg, Frankfurt am Main und München von drei auf sieben zu erhöhen (SAPMO-BArch DY 30/IV 2/2/312, Bl. 8).

${ }^{26}$ Kowalczuk/Mitter, ,Die Arbeiter sind zwar geschlagen' (1995), S. 48 f.

27 In der Arbeiterschaft wurden sogar Rücktrittsforderungen an die Regierung laut. Vgl. Kowalczuk/Mitter, ,Die Arbeiter sind zwar geschlagen' (1995), S. 50.

${ }^{28}$ Erhöhung der Arbeitsnormen durch den Ministerrat am 28.5. 1953 (GBI. Nr. 72, 2. 6. 1953, S. 781); BeschluB des ZK der SED vom 14. 5. 1953, in: Dokumente der SED, Bd. IV, S. $411 \mathrm{f}$.

${ }_{29}$ Weber, Die DDR (2006), S. 42; Kowalczuk/Mitter, ,Die Arbeiter sind zwar geschlagen' (1995). Auch Fricke, Zur Geschichte (1999), S. 37, betont die Enttâuschung der Arbeiterschaft, deren Erwartungen nicht erfüllt wurden, „wāhrend den Bauern, den Kleinunternehmern, Gewerbetreibenden und Handwerkern Zugestāndnisse gemacht wurden". Zum Volksaufstand des 17. Juni ist anläßlich seines 50. Jubilāums 2003 eine Flut von Literatur erschienen. Für einen Überblick über die Neuerscheinungen vgl. Bispinck u.a., Krisen und Aufstände (2004), S. 11-13; Wettig, Der 17. Juni (2003); Fricke/Engelmann, "Tag X“ (2003), S. 7-19; Diedrich, Waffen gegen das Volk (2003), S. 155-165.

so Vgl. Tabelle 3. Eine weitere Ausnahme bilden die Kasernierten Volkspolizisten, deren mit illegaler Auswanderung verbundenen Desertionen ebenfalls seit 1952 angestiegen waren, ihren Höhepunkt aber erst im Juli und August 1953 erreichten. Vgl. Wenzke, Fahnenflucht (1998), S. 260 ff., 284, Anm. 26.
} 
derungen seit Anfang 1954 verbesserte sich darüber hinaus auch bald die Versorgungslage in der DDR."

Soweit die Beschlüsse, an die ein großer Teil der Bevölkerung offensichtlich glaubte: Die Zahl der Flūchtlinge nahm schlagartig ab und zahlreiche bereits geflūchtete Personen kehrten in die DDR zurück. ${ }^{32}$ Doch hielten sich die Reformen in engen Grenzen, denn die Mitte Juni 1953 mit Hilfe von sowjetischen Panzern konsolidierte SED-Herrschaft und die damit zusammenhāngende Stārkung der Hardliner um Ulbricht sorgten dafür, daß sich einige Facetten, nicht aber die Grundlagen von Politik und Gesellschaft in der DDR änderten. Dies wurde vor allem an der Behandlung der Rũckkehrer sichtbar, die ganz anders aussah als in den offiziellen Kommuniqués formuliert. Bei der Durchführung der zentral beschlossenen Politik zeigte sich wieder das unausgesprochene aber wirkungsvolle Zusammenspiel zwischen radikalen Parteivertretern an der Basis und radikalen Politikern an der Spize der SED. Das in der SBZ/DDR exzessiv praktizierte politische Doppelspiel konnte bei der von oben verordneten Liberalisierung nicht wirkungslos bleiben: Die offizielle Rhetorik hatte seit 1945 stets der deutschen Einheit und zentralen Elementen von Rechtsstaatlichkeit und Demokratie gehuldigt, wobei dieselben Redner gleichzeitig dazu aufgerufen hatten, jeden Schritt und jede Maßnahme auf das Wohl der eigenen Partei und die Durchsetzung ihrer "Wahrheit" auszurichten. So verstanden die stark verunsicherten SED-Vertreter an der Basis den Neuen Kurs - āhnlich wie die demokratischen Spielrāume in der zweiten Hälfte der vierziger Jahre - nur als taktisches Manōver, nicht aber als grundsātzliche Neuorientierung. Sobald sich daher Möglichkeiten zur Fortsetzung der radikalen Politik zeigten, wurden sie von vielen kommunistischen Funktionstrāgern - auch gegen die offiziellen Parteibeschlüsse - genutzt.

Ein Teil der angekündigten Erleichterungen wurde daher niemals ernsthaft realisiert, im deutsch-deutschen Reiseverkehr führte der Neue Kurs aber dennoch zu substantiellen Veränderungen: Wurden im ersten Halbjahr 1953 lediglich 7840 Privatreisen nach Westdeutschland genehmigt, waren es im zweiten Halbjahr stolze $1081387 .{ }^{33}$ Die Liberalisierung des Interzonenverkehrs nahmen SED und Regierung nach der Konsolidierung ihrer Macht auch nicht sofort zurück, sondern erweiterten die Genehmigungsspielrãume am 8. September 1953 sogar noch: Das Politbüro bestimmte, „in Ausnahmefällen“ auch Aufenthaltsgenehmigungen für die streng bewachte Sperrzone zu erteilen. ${ }^{\text {H }}$ Allerdings er-

3! Weber, Die DDR (2006), S. 43.

32 Anders als Hirschman, Abwanderung (1992), S. 336, annimmt, sind dic hohen Fluchtzahlen von 1953 nicht auf das Scheitern des Aufstands zurūckzuführen. Der „Bericht über die illegalen Abwanderungen nach dem 9. Juni 1953“ des Staatssekretariats für Innere Angelegenheiten, Abt. Bevōlkerungspolitik, vom 5. 11. 1953 nennt die abnehmenden Zahlen der Auswanderer und die ansteigenden der Rückkehrer und Erstzuziehenden (BArch DO 1/07, Nr. 11780). Auch in den Statistiken der Bundesrepublik nehmen die Zahlen schon im Juli 1953 stark ab. Obwohl die Repression nach dem 17. Juni verschärft einsetzte und viele Menschen verhaftet und aus ihren Firmen entlassen wurden, ging die Zahl der Westabwanderer von 40381 (Juni) auf 17260 (Juli) und 14682 (August) drastisch zurück (Notaufnahmestatistik; āhnlich die HVDVPStatistik; die Zahlen des Staatssekretariats für Innere Angelegenheiten. Abt. Bevölkerungspolitik, vom 5.11. 1953 zeigen die gleiche Tendenz). Zum Zusammenhang zwischen Fluchtbewegung, "Neuem Kurs" und Volksaufstand vgl. Bispinck, Flucht- und Ausreisebewegung (2004).

s3 Jahresbericht der Abt. PM für 1953, BArch DO 1/11, Nr. 914, Bl. 209-219, hier Bl. 213.

s4 SAPMO-BArch DY 30/IV 2/2/322, Bl. 6. Gleichzeitig gestattete das PB den Einsatz weiterer Interzonenzüge, beaufuragte dabei aber auch das AZKW mit der Kontrolle aller Reisenden; ferner durfte die Anzahl der ausgestellten Interzonenpässe 8000 pro Tag nicht überschreiten (SAPMO-BArch DY $30 /$ TV 2/2/312, Bl. 7 f.). 
ließ das Politbūro auf dieser Sitzung auch einschrảnkende Bestimmungen: So nahm es eine Vorlage zur ${ }_{n}$ Regelung der Interzonenreisen für Mitarbeiter des Staatsapparates und des Verwaltungsapparates der volkseigenen Wirtschaft " an, die zwar in allgemeiner Form versicherte, daß auch die benannten Personen von den „Erleichterungen für die Ausstellung von Interzonenpāssen für Privatreisen nach Westdeutschland [...] grundsātzlich nicht ausgeschlossen" seien. Im unmittelbaren AnschluB formulierte sie aber einschränkende Bedingungen, die den zahlreichen Staatsbediensteten - allein in der öffentlichen Verwaltung etwa 234000 Mitarbeiters - eine Westreise fast unmöglich machte. ${ }^{56}$ Ganz offensichtlich hielt sich die SED nur widerwillig und halbherzig auf dem von Moskau und den Straßen der Republik geforderten Neuen Kurs.

Auch ein Beschluß des Politbüros vom Dezember 1953 zeigte die alte politische Härte, mit der die SED-Fūhrung auf die Republikflucht reagierte. ${ }^{37}$ Ein von Plenikowski vorgelegter Bericht und MaBnahmenkatalog enthielt zwar keine direkten Drohungen an die illegalen Auswanderer mehr, wohl aber deutliche Beschimpfungen, die auch die angeblich Verantwortlichen im Westen einschlossen. Entsprechend wurden die Intensivierung des Berichtswesen, mehr Aufklärung, mehr "Wachsamkeit" und regelmäBige ressortübergreifende Besprechungen verabredet. Die am 24. Februar 1954 im Sekretariat des ZK beschlossenen MaBnahmen zur Durchführung dieses Beschlusses ${ }^{58}$ spiegeln die wiedergewonnene Selbstsicherheit der hegemonialen Partei noch stärker: Die Polemik gegen den Westen nahm zu, die Bundesrepublik wurde mit grōbsten Faschismus- und Verelendungsvorwürfen bedacht und die Maßnahmen im eigenen Land sahen neben weiterer Unterstūtzung für Rūckkehrer auch wieder eine Zunahme und Verfeinerung der sicherheitspolitischen Überwachung vor. ${ }^{39}$ So sollten die Zuwanderer und Rückkehrer aus dem Westen eine „ideologische Betreuung“ erfahren, wenn auch „jede plumpe Beobachtung" untersagt blieb.

Wie sich die Berliner Partei- und Regierungsorgane den Kampf gegen die illegale Auswanderung idealiter vorstellten, lãßt sich an einem geschönten Bericht des Generalinspekteurs der Volkspolizei, Seifert, vom 26. Februar 1954 an den Leiter der Abteilung für staatliche und administrative Organe der sowjetischen Hohen Kommission in Karlshorst, Petrow, ablesen: Seit Anfang 1953 werde jede Flucht von der Volkspolizei registriert; in Betrieben, Städten und Kreisen mit besonders hohen Auswanderungsraten würden eigene Untersuchungen durchgeführt; alle betreffenden Organe von Regierung, Polizei, staatlicher Verwaltung und Partei arbeiteten zusammen und viele Fluchtversuche seien durch die Mitarbeit der Bevōlkerung verhindert worden. Daß sich die Wirklichkeit nicht ganz so

s. Zahl der Mitarbeiter in der Öffentlichen Verwaltung einschließlich Sozialversicherung mit Stand vom 31. 8. 1950. Statistisches Jahrbuch der DDR 1957, S. 167.

36 Die politische Verantwortung für Reisen und die damit erleichterten Republikfluchten wurde an die jeweiligen Dienstvorgesetzten delegiert. Anstelle von Besuchen bei Verwandten im Westen wurde empfohlen, diese in die DDR einzuladen. Für machtpolitisch sensible Bereiche wie MdI, MdJ und Oberstes Gericht galten darüber hinaus "besondere Anweisungen“ (SAPMO-BArch DY 30/IV 2/2/322, Bl.6, 86-89).

37 Am 15.12.1953 beschloB das PB "weitere Maßnahmen im Kampf gegen die Republikflucht" (SAPMO-BArch DY 30/IV 2/2/337, Bl. 7f., 49-52).

s8 SAPMO-BArch DY 30/J IV 2/3/420, Bl. 17-25.

99 Andrea Schmelz zufolge markieren diese zu Beginn des Jahres 1954 beschlossenen MaBnahmen "den Anfang eines akribisch geführten Kontroll- und Überwachungsapparates über die West-Ost-Migranten in die DDR“. Schmelz, Migration und Politik (2002), S. 111. 
einfach gestaltete, deutete Seifert nur an: Seit einiger Zeit würden fluchtverdächtigen und ausreisewilligen Personen nicht mehr ihre Personalausweise abgenommen, denn die Erfahrungen haben gezeigt, daB damit nicht die Republikflucht, sondern in der Mehrzahl nur die Mitnahme der Personalausweise verhindert wurde. " ${ }^{40}$ Obwohl die Politik keineswegs so gradlinig und erfolgreich verlief, wie Seifert sie beschrieb, zeigt der Bericht, daß die Liberalisierungstendenzen Mitte 1953 nur von kurzer Dauer gewesen waren. Das Ziel, durch eine liberalere Politik ein tragbares gesellschaftliches Arrangement zu finden, wurde aufgegeben.

Nachdem SED und Staatsorgane schon in den Monaten nach dem 17. Juni 1953 mit groBer Härte gegen vermeintliche Gegner und gegen Abweichler in den eigenen Reihen vorgegangen waren, ${ }^{11}$ machte der vierte Parteitag der SED im April 1954 das ,offizielle' Ende des Neuen Kurses deutlich erkennbar. ${ }^{12}$ Wiederum verschärfte die SED ihre sozialistische Rhetorik und wiederum wurde der wirtschaftspolitische Kurs - etwa durch den weiteren Ausbau der Schwerindustrie - radikalisiert. Wie in den Jahren zuvor konnten aber auch jetzt wieder „die Schwächen der Wirtschaft [...] trotz gewaltiger Anstrengungen nicht überwunden" werden, wodurch sich die Instabilităt der DDR wieder vergrößerte: „Die radikalen Strukturveränderungen hatten kein florierendes System hervorgebracht, sondern eine krisenhafte Gesellschaft. Die sozialen Umschichtungen blieben ohne breite Zustimmung. ${ }^{43}$

\subsection{Weitere Maßnahmen gegen Flucht und Abwanderung bis zum Mauerbau}

Unter dem Eindruck des Neuen Kurses hatten sich erkennbar weniger Menschen für den Weg in den Westen entschieden. ${ }^{44}$ Allerdings war nur der unmittelbare Druck durch Enteignungen, Repressionen oder den Zwang zur Mitgliedschaft in Genossenschaften abgemildert worden, nicht aber das allgemeine Klima der politischen Intoleranz und wirtschaftspolitischen Einseitigkeit. Daher bedeuteten die Fluchtzahlen auch nur im Verhãltnis zu den Monaten der extremsten Abwanderung in der ersten Jahreshälfte von 1953 eine Entspannung. Absolut waren die Zahlen für die DDR weiterhin bedrohlich hoch und das einmal erkannte Problem der Auswanderung blieb daher auch unter staatlicher und parteilicher Beobachtung, wofür in besonderem Maße die Hauptverwaltung Deutsche Volkspolizei und die Abteilung Staat und Recht beim ZK der SED verantwortlich zeichneten. Beide Apparate beobachteten die Flucht- und Abwanderungsbewegung aufmerksam. schrieben zahlreiche Berichte, erstellten Statistiken, untersuchten die Motive und Ursachen der Fliehenden und initiierten politische Maßnahmen oder reagierten auf solche. th $^{5}$

\footnotetext{
40 BArch DO 1/11, Nr. 962, Bl. $180 \mathrm{f}$.

4 Fricke, Zur Geschichte (1999), S. 72-78; Kowalczuk, Volkserhebung (1995), S. 160-167.

42 Weber, Die DDR (2006), S. $43 \mathrm{ff}$.

43 Weber, Die DDR (2006), S. 45.

* Sowohl nach den Zahlen der Anträge im Notaufnahmeverfahren der Bundesrepublik (vgl. die Tabelle bei Heidemeyer, Flucht und Zuwanderung (1994), S. 338f.) als auch nach denen der ZV für Statistik der DDR (vgl. Bericht über die Entwicklung der Wanderung über die Grenzen der Deutschen Demokratischen Republik bis zum 31. Dezember 1961 in: BArch DE 2, Nr. 1721, S. 15 f.) flohen in der zweiten Jahreshälfte 1953 nur etwa halb so viele Bürger in den Westen wie zwischen Januar und Juni.

45 Die meisten dieser Vorgānge finden sich in folgenden Akten: BArch DO 1/11, Nr. 960-967 und SAPMO-BArch DY 30/IV 2/13/393-402.
} 
Trotz diverser Aktivitāten setzte sich in den Behörden schnell die Einsicht durch, daß administrative, polizeiliche und politische Maßnahmen gegen den Weggang in den Westen weitgehend wirkungslos waren. Anfang August 1954 lehnte die Hauptabteilung PaBund Meldewesen den Vorschlag der Betriebsparteiorganisation des Edelstahlwerkes Dōhlen, von jedem besuchsweise in den Westen Reisenden eine Urlaubsbescheinigung zu verlangen, mit dem Hinweis ab, dies sei „ein Versuch, der Republikflucht mit formalen Mitteln vorzubeugen. ${ }^{46}$ Die von Partei und Polizei selbst initiierten MaBnahmen waren aber nicht weniger formal. Daher scheinen diese häufig nicht nur oder nicht einmal in erster Linie dem Kampf gegen die Republikflucht gedient zu haben. Wichtiger war wohl der Nachweis der Behörde, überhaupt aktiv zu sein und für die staatliche Autoritāt zu kämpfen, auch wenn dabei zumeist nicht mehr herauskam als das „Herumkurieren an Erscheinungen einer systeminternen, nicht zu beseitigenden Ursache ${ }^{4.17} \mathrm{DaB}$ die Einsicht in die eigene Wirkungslosigkeit verbreiteter war als zugegeben, zeigen die zahllosen Stellungnahmen, die genauso klangen wie die Antwort der Hauptabteilung PM vom 22. Mai 1954 an Seifert, der hatte wissen wollen, ob Ehefrauen ihren republikflūchtigen Ehemännern nachfolgen dürften: „Bei Ablehnung der Übersiedlung ist zu erwarten, daB sie republikflüchtig werden. 48

Das Problem bestand nicht in einzelnen Verordnungen, Gesetzen oder Verboten, sondern in der offenen Grenze der DDR. Die Westgrenze war durch das im Mai 1952 eingeführte Grenzregime zwar nicht mehr ungehindert zu passieren, Berlin aber blieb eine offene Stadt, in der fast jeder die Systemgrenze zu FuB, per S-Bahn, Fahrrad oder Auto ohne größere Komplikationen überqueren konnte. Angesichts der nationalen und internationalen Kräfteverhāltnisse führte die Erfolg- und Hilflosigkeit im Kampf gegen den massenhaften Wegzug aber nicht zu einer offenen Kapitulation Ost-Berlins, da dies der Aufgabe des gesamten Staates gleichgekommen wäre. Statt dessen blieb es bis zum August 1961 bei einzelnen, hāufig unkoordinierten und nicht selten sogar widersprüchlichen Maßnahmen, wobei das offizielle Beobachten, Sammeln und Berichten zu den Haupttātigkeiten gehörte. ${ }^{49}$ Damit beschäftigten sich auf lokaler, regionaler und zentraler politischer Ebene viele Staats- und Parteimitarbeiter, die zahlreiche Akten hinterließen und das Problem der Republikflucht ins allgemeinpolitische Weltbild in der DDR einordneten: Die Abwanderung in den Westen bestätigte die eigene dichotome Wahrnehmung des Ost-West-Systemgegensatzes, wobei die entscheidenden Ursachen fast immer nur auf der westlichen Seite verortet wurden. In den eigenen Reihen machten die SED und ihre Staatsorgane nur individuelle Fehler aus, die vorwiegend damit erklärt wurden, daß es den Kritisierten noch an der notwendigen politischen Eindeutigkeit mangele. ${ }^{50}$

Ihre verbohrte Haltung reflektierte die Position der politischen Fūhrung der DDR nach den Unruhen im Sommer 1953: Diese hatten nicht nur eine verbreitete Unzufriedenheit

${ }^{46}$ Dok. 23; Dok. 23 a.

47 Lemke, Berlinkrise (1995), S. 49.

48 BArch DO 1/11, Nr. 962, BI. 199.

49 Die Sammlungs- und Berichtstātigkeit nahm bisweilen groteske Ausmaße an und führte zu interner Kritik. So stellte sich für den stellvertretenden Kaderleiter der TH Dresden die Frage, ob die zweimalige Ablieferung von Monatsberichten zur Republikflucht „weckmäßig und notwendig" sei, und ob "überflüssige Schreibarbeiten " nicht besser zu vermeiden seien. Schreiben an das Staatssekretariat für Hochschulwesen, Kaderabteilung, 3. 1. 1958, BStU ZA, MfS-AS, Nr. 2487/67 Bd. I, Bl. 4.

so Vgl. dazu Kap. 4.3. 
in der Bevölkerung zum Ausdruck gebracht, sondern auch die Einsatzbereitschaft der UdSSR für den ostdeutschen Staat erhōht, so daß sich die DDR-Führung in einer erheblich gesicherteren Position wußte als zuvor. Das militärische Eingreifen der Sowjetunion im Sommer $1953 \mathrm{kam}$ einer Bestandsgarantie gleich, die durch die schrittweise Übertragung der Souveränitāt bis 1955 offiziell besiegelt wurde. ${ }^{51}$ Die von außen garantierte Sicherheit der DDR und die Erfahrung vom Sommer 1953, daß sich selbst unter den Arbeitern zahlreiche Gegner der SED befanden, stärkten nur die - zuweilen paranoide Aufmerksamkeit gegenüber möglichen Widersachern im eigenen Land, nicht aber das Gespür für die eigentlichen Ursachen der fortgesetzten Auswanderung. Eine Konsequenz war die weitgehende Hilflosigkeit und Passivitāt der Führungsgremien der DDR gegenūber der Flucht. Alle Aktivitāten einzelner Behörden gegen die Republikflucht blieben bis zum Mauerbau weitgehend erfolglos. Daher gab es in den füfziger und sechziger Jahren nach dem ,Neuen Kurs' nur noch zwei zentrale politische Einschnitte in der Geschichte der deutsch-deutschen Fluchtbewegung: Zum einen verschärfte die Regierung Ende 1957 das Paßgesetz und schrānkte die Reisemöglichkeiten der DDR-Bevölkerung ein, nachdem sie 1956 und 1957 die hohen Fluchtzahlen nicht hatte reduzieren kōnnen. Zum anderen steigerte sich die auf Berlin konzentrierte internationale und deutsch-deutsche Krise seit 1960 bis zum bekannten Ende, dem Mauerbau am 13. August 1961.

Nach einer Zeit der Ruhe zeigte sich schon im Herbst 1955 ein wieder erhōhtes Problembewußtsein gegenüber der erneut ansteigenden Fluchtwelle. So befaßte sich etwa das Sekretariat des ZK im Oktober 1955 mit der Flucht von Jugendlichen, ${ }^{52}$ im Spätsommer 1955 wurde wiederholt vorgeschlagen, den Umzug von Ost- nach West-Berlin wieder - wie bereits vor dem 30 . Juni 1953 - genehmigungsplichtig zu machen, ${ }^{53}$ und im Oktober 1955 und Anfang 1956 wies der Chefinspekteur der Volkspolizei (Seifert) verschiedene Minister brieflich auf die Republikflucht in ihren Arbeitsbereichen und ihren nachgeordneten Behörden und Betrieben hin. ${ }^{54}$ Auch einzelne Polizeiabteilungen schlugen immer hãufiger Maßnahmen gegen die illegale Auswanderung vor, wie den Einzug von Personalausweisen, die Reduzierung von Reisegenehmigungen in den Westen, stärkere Kontrollen beim Zugang nach Ost-Berlin, die strengere Überprüfung von Besuchern aus der Bundesrepublik, die Enteignung von Geflüchteten und verschärfte Beobachtungs- und Bespitzelungsauftrāge an die Abschnittsbevollmāchtigten der Volkspolizei, die zum Beispiel alle Zeitungsanzeigen nach Wohnungsauflösungen und Möbelverkāufen auswerten sollten. ${ }^{55}$

\footnotetext{
51 Schon am 25. 3. 1954 übergab die UdSSR der DDR mit der Souverānitátserklärung ,erweiterte' Souveränitātsrechte. Am 20.9. 1955 schloß die UdSSR dann den ,Vertrag über die Beziehungen zwischen der DDR und der UdSSR“, der die DDR für souverān erklārte, und lōste ihre Hohe Kommission auf (Weber, Die DDR [2006], S. 47). Seit dem 1. 12. 1955 übernahm die DGP alleine die Bewachung und Kontrolle ihrer Grenzen, wovon nur der alliierte Verkehr auf der Transitstrecke zwischen Westdeutschland und West-Berlin ausgenommen blieb (Lapp, Die Transitwege [1999], S. 102 ff.; Zeittafel zur Militärgeschichte [1989], S. 55).

32 Protokoll der Sitzung des ZKSekr vom 12. 10. 1955, SAPMO-BArch DY 30/J IV 2/3-490, BI. I f.

5s Leiter der HA PM, Fischer, am 31.8. 1955 an Chefinspekteur Grünstein (BArch DO 1/11, Nr. 963. BI. 46 f.); Chefinspekteur der VP, Seifert, im September 1955 an Innenminister Maron (BArch DO 1/11. Nr. 963, Bl. 45).

34 BArch DO 1/11, Nr. 963, Bl. 49 ff.; BArch DO 1/11, Nr. 963, Bl. $138 \mathrm{ff}$.

ss BArch DO 1/11, Nr. 963, Bl. 142-146; BArch DO 1/11, Nr.963, Bl. 177 ff.; BArch DO 1/11, Nr. 637. Bl. 46.
} 
Die Ende 1957 verabschiedete Novellierung des Paßgesetzes der DDR ${ }^{56}$ und das damit einhergehende schärfere Vorgehen gegen Auswanderungswillige und illegale Grenzübertritte zeigten schließlich deutliche Wirkung: In der Bevölkerung verbreitete sich zwar erheblicher Unmut, ${ }^{57}$ aber die Zahl der Republikfluchten nahm stark ab. Dies war - anders als Mitte 1953 - in besonderem Maße auf die Kriminalisierung und Repression zurūckzuführen. Allerdings erleichterte auch die politische und wirtschaftliche Lage das Verbleiben in der DDR. Seit 1957 und in der ersten Jahreshälfte 1958 stieg die Industrieproduktion - nach Angaben der DDR - um acht bzw. zwölf Prozent an und die Konsumgüterindustrie machte Fortschritte, die sich im Lebensstandard der Bevōlkerung bemerkbar machten. Beispielsweise verschwanden im März 1958 die Lebensmittelkarten und die Rationierung von Fleisch, Fett und Zucker. ${ }^{58}$ Große Teile der Bevölkerung hatten sich offenbar in der DDR eingerichtet, genossen deren - im Vergleich zur Zusammenbruchsgesellschaft von 1945 - herausragende soziale Errungenschaften und schätzten das politische Klima weniger repressiv ein als zuror.

Obwohl die Zahl der Republikfluchten 1958 und 1959 im ganzen stark zurückging, ${ }^{59}$ blieb das Thema auf der Tagesordnung. Die politischen Gremien beschäftigten sich ebenso wie die Medien und einzelne Behörden - weiterhin damit. Oft ging es dabei um die allgemeine Fluchttendenz, bewegten sich die Zahlen doch weiterhin in den meisten Monaten im fünfstelligen Bereich. Da aber besonders viele Mediziner, Lehrer, Hochschullehrer sowie andere Fachleute und Spezialisten die DDR verließen, die für deren Wirtschaft und Gesellschaft besonders wichtig waren, ${ }^{60}$ richteten sich zahlreiche offizielle Aktivitäten auf diese Berufsgruppen. ${ }^{61}$

Die Entscheidung dieser Fachleute, die DDR zu verlassen, orientierte sich nur in nachgeordneter Weise an einzelnen Gesetzen und Verboten, die sich auf Fragen der Grenze und des Grenzübertritts bezogen, zumal diese durch das Schlupfloch in Berlin

\footnotetext{
56 Vgl. dazu oben, Kap. 3.1, S. $48 \mathrm{f}$.

57 So verweist z.B. eine Ratsvorlage aus Karl-Marx-Stadt vom 31.5. 1958 wiederholt auf Ärger über das Gesetz in der Bevölkerung: S. 3 f., 7 (BArch DO 1/34, Nr. 21725).

5* Weber, Die DDR (2006), S. 50. Zur Wirtschaftsgeschichte der DDR immer noch grundlegend: Roesler, Sozialistische Planwirtschaft (1978); vgl. jetzt auch Schwarzer, Zentralplanwirtschaft (1999); Steiner, Von Plan zu Plan (2004). Zur Konsumgeschichte vgl. Merkel, Utopie (1999); Kaminsky, Wohlstand (2001); Heldmann, Herrschaft, Wirtschaft, Anoraks (2004); Stitziel, Fashioning Socialism (2005).

39 Nach Angaben der Zentralverwaltung für Statistik wurden 1958 rund 216000 und 1959144000 Būrger republikflüchtig gegenüber 315000,364000 bzw. 352000 in den Jahren 1954 bis 1956 (vgl. Tabelle 1). Die westdeutschen Angaben bestātigen diesen Trend. Dazu Heidemeyer, Flucht und Zuwanderung (1994), S. 37-48.

so Wāhrend die Gesamtzahl der Auswanderer von 1957 auf 1958 - je nach Statistik - um ca. ein Drittel zurückging und 1959 sogar weniger als halb so viele Menschen auswanderten wie 1957, stieg die absolute Anzahl z.B. bei den Ärzten und den Wissenschaftlern zwischen 1957 und 1958 auf das Doppelte, bei den Lehrern immerhin um ein Drittel. 1959 gingen die absoluten Zahlen zwar auch bei diesen Berufsgruppen zurück, doch hatten sich ihre Anteile an der gesamten Auswanderung gegenüber 1957 verdoppelt (Wissenschaftler, Forscher) bzw. verdreifacht (Ärzte), vgl. Tabelle 3. Zu den Ärzten auch: Ernst, Prophylaxe (1997), S. 54-59; Ernst, Von der bürgerlichen zur sozialistischen Profession (1996), S. 27 f.; zu Ingenieuren: Augustine, Frustrierte Technokraten (1996), S. 54; zu Wissenschaftlern: Jessen, Akademische Elite (1999), S. 92 f.; Conelly, Zur „Republikflucht“ (1994); zu Lehrern: Geißler, Republikflucht von Lehrern (1992); Geißler, Geschichte des Schulwesens (2000), S. 503-511.

${ }_{61}$ Vgl. z.B.: Bericht der HA PM über besonders stark steigende Republikflucht von Ärzten, Lehrern und Ingenieuren (BArch DO 1/11, Nr. 965, Bl. 30 f.); Vorschlag des ZKSekr an PB vom 2. 7. 1958, im Kontext der Republikflucht die Lage der Ärzte zu behandeln (SAPMO-BArch DY 30/J IV 2/3-606, B1.5).
} 
jederzeit relativ leicht umgangen werden konnten und die materiellen Einbußen gerade für diese Berufsgruppen durch die attraktiven Angebote aus dem Westen einfach zu kompensieren waren. Viel wichtiger war daher die politische Stimmung in der DDR. Nach der allgemeinen Beruhigung der Lage hatte die SED-Führung wieder damit begonnen, ihre sozialistische Umgestaltungspolitik zu radikalisieren. Auf dem fünften Parteitag der SED vom 10. bis 16. Juli 1958 festigte Ulbricht seine Führungsposition und verkündete seine Idee vom "Ūberholen" der Bundesrepublik und der "Vollendung" des Sozialismus. ${ }^{62}$ Dazu wies der Parteitag den Weg zur Beschleunigung der ${ }_{n}$ sozialistischen Entwicklung " in der Wirtschaft, was für private Landwirtschafts- und Handwerksbetriebe weitere Zwangskollektivierungen bedeutete und für private Handels- und Industriebetriebe weitere Enteignungen. Die Folgen waren verheerend, denn die Produktion ging stark zurück, die Versorgung der Bevölkerung verschlechterte sich erheblich und viele Selbständige verließen ihre Betriebe und Hāuser und gingen in den Westen, weil sie keine Möglichkeit mehr sahen, ihren bisherigen Status zu behaupten. ${ }^{69}$ In dieser Zeit wurden weitere, vor allem für Akademiker spürbare politische Schritte vorgenommen wie die dritte Hochschulpolitische Konferenz der SED vom 28. Februar bis 2. Mārz 1958 zur Einführung der "sozialistischen Universităt“, ${ }^{64}$ die vom ZK im Januar 1959 beschlossenen Thesen zur ${ }_{n}$ sozialistischen Umgestaltung des Schulwesens ${ }^{*}$ oder die Bitterfelder Konferenz im April 1959 und die Durchsetzung des sozialistischen Realismus in der bildenden Kunst. 65

Das in der ganzen Bevölkerung verbreitete Unbehagen über die Lage in der DDR ãußerte sich seit dem Frühjahr 1960 wieder in erkennbar ansteigenden Flüchtlingszahlen. Hatten die DDR-Behörden für 1959 bloß 144225 Menschen gezāhlt, die in den Westen geflüchtet waren, stieg die Zahl 1960 wieder um vierzig Prozent auf 202711 an.66

Die politischen Institutionen erkannten die Wirkung ihrer Politik recht bald, zumal Ulbricht gegenüber Chruschtschow schon im Mai 1958, also vor dem fünften Parteitag, geäußert hatte, daß nur ein wirtschaftliches Schnellprogramm das West-Ost-Gefālle ausgleichen kōnne. ${ }^{67}$ Vor allem der Polizeiapparat merkte 1960 schnell, daß die Anzahl der illegalen Auswanderer im Vergleich zum Vorjahr extrem anstieg, ${ }^{, 6}$ stellte allerdings in offiziellen Berichten die eigenen Erfolge im Kampf gegen die Republikflucht heraus: So be-

\footnotetext{
${ }^{62}$ Zum Parteitag und seinen Folgen vgl. Hoffmann, DDR unter Ulbricht (2003), S. 78 f.

63 Weber, DDR Grundriß (2000), S. 78 f., 87 f. Weber, Die DDR (2006), S. 51 ff. Zu den sozialen Erschũtterungen, die diese Politik auf dem Land bewirkte, vgl. v.a. Osmond, Kontinuitãt (1996).

a Anfang 1958 schnellten die Zahlen der republikflüchtigen Nachwuchswissenschafter an den Universitāten hoch, als die SED den Universitāten mit der Einführung einer neuen Assistentenordnung einen weiteren Politisierungsschub verordnete: Im ersten Halbjahr 1958 flohen 224 wissenschaftiche Mitarbeiter und Hochschullehrer, während es im gleichen Zeitraum 1957 nur 53 gewesen waren (Staatssekretariat für das Hoch- und Fachschulwesen, Kaderabteilung, „Analyse der Republikflucht", 8. 8. 1959, abgedruckt in: Conelly, Zur „Republikflucht“ [1994], S. 337-343, hier S. 338). Als die SED-Führung feststellte. $\mathrm{da} B$ die Flucht zu einem deutlichen Mangel an Nachwuchskräften geführt hatte, verordnete sie am 16.9. 1958 eine zurūckhaltendere Gangart (Jessen, Akademische Elite [1999], S. 92 f.).

$65 \mathrm{Vgl}$. Weber, Dic DDR (2006), S. 54 f.

66 Tabelle 1.

67 Vgl. Major, TorschluBpanik (2000), S. 224.

68 Vgl. z.B. Bericht der HA PM vom 16. 7. 1960, in dem ein „erheblicher Anstieg der Republikfluchten“ konstatiert wird, der „beinahe alle soziale Gruppen“ erfasse (BArch DO 1/11, Nr. 966, Bl. 170-182, hier B1. 170).
} 
richteten die Hauptabteilungen PM und Kriminalpolizei am 16. Juli 1960 nicht nur von den vielen tausend Flüchtlingen, sondern behaupteten auch, innerhalb weniger Monate mehr als 10000 Personen erfolgreich von der Republikflucht abgehalten zu haben. Tatsāchlich leitete die Polizei vor allem auf den Straßen und Schienenwegen rund um Berlin verschärfte Kontrollen und Überprüfungsmaßnahmen ein. Diese erschwerten zwar die Flucht, im ganzen aber blieben sie erfolglos, solange Berlin seine offene Grenze behielt. Recht unverblümt illustrierte die Transportpolizei ihre Hilflosigkeit bei den Straßen- und Bahnkontrollen in einem Bericht über die Flucht von Bürgern aus dem Sũden der DDR: Um die Zugbegleitkommandos der Polizei zu täuschen, fuhren Sachsen und Thüringer für wenige Tage nach Mecklenburg in Urlaub, um dort Rūckfahrkarten in ihre Heimatstädte zu lösen, die sie durch Berlin führten. So kamen sie in die geteilte Stadt, ohne bei den Kommandos Verdacht zu wecken. ${ }^{\theta}$

Der erneute Anstieg der Republikfluchten rief offenbar auch das MfS auf den Plan. Am 4. Mai 1960 erlieB Mielke „MaBnahmen zur Einengung der Republikfluchten“, in die „alle[] Mitarbeiter aller Linien“ sowie das „gesamte Netz der inoffiziellen Mitarbeiter" einbezogen werden und die „in engster Zusammenarbeit [...] mit Partei- und Staatsorganen, mit der Deutschen Volkspolizei, der Transportpolizei, der Deutschen Grenzpolizei und des AZKW [Amt für Zollkontrolle und Warenverkehr] “ durchgeführt werden soll-

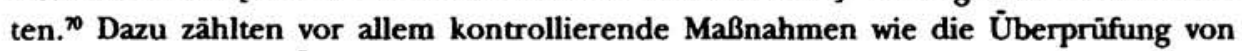
Westkontakten, die Überwachung von Personen, die mit Partei- oder Staatsorganen in Konflikt geraten oder deren Angehörige geflohen waren sowie verschärfte Grenz- und Zugkontrollen, aber auch die Unterstützung von Propagandamaßnahmen und die Aufklärung von Ursachen der Republikflucht, wobei ${ }_{n} \mathrm{MaBnahmen}$ zur Beseitigung einzuleiten “ waren, , falls es sich um Fehler und Mängel oder um Unzulänglichkeiten von Staatsund Wirtschaftsorganen " handelte. Weitere inoffizielle Maßnahmen wie Postkontrollen sowie die Gewinnung von Taxichauffeuren, Fahrkartenverkāufern und Briefträgern als Inoffizielle Mitarbeiter (IM) wurden wenig später ergānzt." IM sollten nicht nur auf dem Gebiet der DDR, sondern auch in Westdeutschland, z. B. zur ${ }_{\text {Absicherung der }}$ DDR-Teilnehmer an wissenschaftlichen Tagungen und Kongressen " eingesetzt werden. ${ }^{22}$ Schwerpunkt der Arbeit der IM gegen die Republikflucht waren jedoch die West-Berliner und westdeutschen Notaufnahme- und Flüchtlingslager. Dazu hatte es bereits ein Jahr zuvor eine konkrete Arbeitsrichtlinie gegeben. ${ }^{73}$ In den Notaufnahmestellen Marienfelde, Gießen und Uelzen solite "ein qualifiziertes Netz von inoffiziellen Mitarbeitern" aufgebaut werden, wobei vor allem „den Angestellten der Registratur grosse Bedeutung beizumessen" war, da diese Einblick in die Flūchtlingsakten hatten. Das auf diese Weise beschaffte Material sollte für Propagandaaktionen in Presse und Rundfunk verwendet werden. Ferner sollten die Angestellten "durch stāndige Aufklärungs- und Zersetzungsaktionen" beeinflußt werden, um „Verwirrungen und Ansatzpunkte für Werbungen zu schaf-

\footnotetext{
6s HVDVP, HA Transportpolizei, Leiter der Abteilung ZBK, Major der VP Hāhnlein, am 14. 10. 1960 an nachgeordnete Transportpolizei, BArch DO 1/11, Nr. 1428, Bl. 14 f., auch ebd., Bl. 16 f.

70 Anweisung Nr. 1/60 (Dok. 24).

71 Politisch-operative Maßnahmen und Erfahrungen zur Einschränkung und Verhinderung von Republikfluchten in Ausführung der Anweisung Nr. 1/60 vom 4. 5. 1960“, 7. 7. 1960 (Dok. 24 a)

72 Dok. 24 a.

73 Arbeitsrichtlinie für die Hauptabteilung VII/2 und die Abteilungen VII/2 in den Bezirksverwaltungen“, 5. 5. 1959. BStU ZA, MfS-BdL, Nr. 002388, Bl. $1-8$.
} 
fen“, und der "Arbeitsablauf in den Notaufnahmeverfahren durch operative Maßnahmen spürbar" gestört werden. Auch in den Flüchtlingslagern sollten IM für „aktive Zersetzungs-, Flugblatt- und Briefaktionen" gewonnen werden, um zu erreichen, daß "der Arbeitslauf in den Lagern erheblich gestört und die Unzufriedenheit unter den Republikflüchtigen gesteigert wird“. Ziel war es letztendlich, mōglichst viele Flūchtige „von der Richtigkeit der Rückkehr in die DDR zu überzeugen“, wobei vor allem Spezialisten zu gewinnen waren. Das MfS nutzte also den Strom der Republikflüchtigen, um zahlreiche IM unauffallig in die Bundesrepublik zu schleusen, ${ }^{74}$ wo sie nicht nur in Flüchtlingslagern als Agenten tātig wurden. Auch der wohl bekannteste DDR-Spion, Gũnter Guillaume, wurde vom MfS als angeblicher Flūchtling über das Notaufnahmelager Marienfelde nach Westdeutschland geschleust. Noch im Mãrz 1961 arbeitete das MfS einen Entwurf aus, der folgende Schritte vorsah: IM sollten in Westdeutschland Personen diskriminieren und ausschalten, „die propagandistisch zur Forcierung der R[epublik]-Flucht beitragen“, sie sollten "Mißbehagen, Mißgunst und Mißtrauen gegen R[epublik]-Flüchtige“ verstärken, Republikflūchtige persōnlich diffamieren, um sie für westdeutsche Dienstund Arbeitsstellen „verdāchtig und untragbar zu machen“, und prominente Flüchtige als unglaubwürdig hinstellen. ${ }^{75}$

Welche dieser Aktionen tatsāchlich durchgeführt wurden und inwieweit sie von Erfolg gekrönt waren, läßt sich aufgrund der in der Einleitung angesprochenen schwierigen Quellenlage nur zum Teil feststellen. ${ }^{76}$ Erfolgreich waren die in Marienfelde tātigen IM vor allem hinsichtlich der Materialbeschaffung. Zahlreiche Unterlagen aus dem Notaufnahmeverfahren, darunter Anträge auf Notaufnahme und Bescheide der Aufnahmebehörde, gelangten auf konspirativen Wegen in die Hānde der Staatssicherheit. " Die gestohlenen Dokumente wurden vom Ministerium ausgewertet, vor allem hinsichtlich der Motive der Geflüchteten. ${ }^{78}$ Ein Beispiel für die nachträgliche Diffamierung von Republikflūchtlingen im Westen ist der Fall von Dieter Hennemann. Dieser war, nachdem er aus politischen Gründen aus dem Schuldienst entlassen worden war, im Dezember 1950 nach West-Berlin geflūchtet. Aufgrund seiner Flucht und seiner spāteren Tătigkeit für das „Informationsbüro West" wurde er von Mitarbeitern des Staatssicherheitsdienstes "bearbeitet". So erhielt seine Frau einen Brief, in dem Hennemann der ehelichen Untreue und des Verkehrs mit Homosexuellen bezichtigt wurde. In Lokalen und Telefonzellen im Wohnviertel des Ehepaares wurden vervielfältigte Heftchen ausgelegt, die eine diffamierende

\footnotetext{
74 Dazu die ehemaligen HV A-Mitarbeiter Richter und Rōsler: „Schnell erkannte die HV A die damit [mit der Fluchtbewegung] verbundenen operativen Möglichkeiten. Nicht wenige dieser Umsiedler konnten sich nämlich sehr effektvoll als politische Flüchtlinge darstellen; andere zogen bald Profit aus der Wirtschaftswunderzeit. Solche Möglichkeiten der beruflichen und sozialen Eingliederung wurden bewußt genutzt, indem einige der făhigsten inoffiziellen Mitarbeiter (IM) der HV A den Auftrag erhielten, mit geeigneter Legende in den Westen zu gehen und sich dort [...] eine Existenz aufzubauen, die spãter für die Spionagetātigkeit auswertbar war." Richter/Rōsler, Westspione (1992), S. 33. Vgl. auch Knabe u.a., West-Arbeit (1999), S. 78 f.

75 Entwurf: „Maßnahmen und Vorschläge zur Bekãmpfung der Republikflucht (Ergãnzung zur Anweisung $\mathrm{Nr} .1 / 60$ v. 4.5.1960)", 2.3.1961 (Dok. 24 b).

76 Die einschlägigen Arbeiten von Knabe u.a., West-Arbeit (1999) und Knabe, Unterwanderte Republik (1999), gehen auf die West-Arbeit des MfS zur Bekāmpfung der Republikflucht nicht nãher ein.

${ }_{77}$ Diese Unterlagen finden sich u.a. in folgenden Akten der BStL: MfS-AS, Nr. 231/63; MfS-HA VI, Nr. 4376; MfS-HA VI, Nr. 8742.
}

${ }^{76}$ BStU ZA, AS 109/65, Bd. 10, Bl. 8, zitiert nach Eisenfeld. Flucht und Ausreise (2002), S. 343. 
und durch Lügen und Verdrehungen entstellte Lebensgeschichte Hennemanns enthielten. ${ }^{79}$ Auch Versuche von Zersetzungsmaßnahmen in Flüchtlingslagern lassen sich nachweisen. So hatte etwa zum 15. März 1956 eine Delegation des Bundesrates einen Besuch im Flūchtlingslager Berlin-Marienfelde angekündigt. Einen Tag vorher wurden in den verschiedenen West-Berliner Lagern angeblich amtliche Schreiben lanciert, in denen die Flüchtlinge aufgefordert wurden, sich wegen Unklarheiten in ihren Papieren am folgenden Tag um 9.30 Uhr in einer bestimmten Abteilung des Lagers Marienfelde zu melden. Eine Ansammlung verunsicherter Flūchtlinge, die nach besagter Abteilung suchten, hātte sicher einen schlechten Eindruck bei der zum gleichen Zeitpunkt eintreffenden Bundesratdelegation hinterlassen. Doch konnte die Aktion noch rechzeitig verhindert werden, nicht zuletzt weil die Unterwanderung des Lagers Marienfelde durch die Stasi den Behôrden schon frühzeitig bekannt war. ${ }^{\circ 0}$ Für die fluchtwilligen DDR-Bünger gravierender war freilich eine andere Maßnahme des Staatssicherheitsdienstes. 1958 gelang es, den TopAgenten Gōtz Schlicht alias „Dr. Lutter“ an der Spitze der im Lager Marienfelde tätigen Außenstelle des Untersuchungsausschusses freiheitlicher Juristen zu installieren. Schlicht befragte ankommende Flūchtlinge gezielt nach Personen, die ihnen bei der Flucht geholfen hatten oder die selbst Fluchtabsichten hegten. Diese Informationen leitete er an die MfS-Zentrale in Berlin weiter. Die betroffenen Personen, zwischen Mârz 1958 und August 1961 waren dies mindestens 650, wurden in der DDR überprüt, überwacht, festgenommen und der Beihilfe zur bzw. der Vorbereitung der Republikflucht beschuldigt. ${ }^{81}$ Auf diese Weise konnten zwar zahlreiche Republikfluchten verhindert werden, angesichts des anhaltenden Flüchtlingsstroms waren diese mit hohem Aufwand erzielten Erfolge jedoch nur ein Tropfen auf den heißen Stein.

Auch die konspirativen MaBnahmen des Staatssicherheitsdienstes haben mithin die Fluchtbewegung in den Westen - wie die Maßnahmen aller anderen Institutionen auch nicht nennenswert einschränken können. Trotzdem wurden vom MfS noch bis wenige Wochen vor dem Mauerbau neue Anstrengungen zu diesem Zweck unternommen: Am 8. Juli 1961 erklärte Mielke die ${ }_{n}$ politisch-operative Arbeit zur Vorbeugung und Verhinderung von Republikfluchten“ zur „entscheidendste[n] Schwerpunktaufgabe“ und beauftragte einen verantwortlichen Mitarbeiter, Oberst Harnisch, mit der Koordination aller MaBnahmen. ${ }^{82}$

Doch wāhrend das MfS noch behauptete, ${ }_{n} \mathrm{daB}$ es mōglich und notwendig ist, die Republikflucht durch entsprechende Gegenmaßnahmen einzuengen ${ }^{483}$, war nicht nur der Polizei, sondern auch den politisch Verantwortlichen bereits klar, daß nur eine umfassende Kontrolle der gesamten Bevölkerung oder eine vollständige Überwachung der Grenze die Auswanderung wirkungsvoll eindämmen konnte. Diese Erkenntnis machte alle Institutionen, die politisch oder administrativ mitverantwortlich waren, im Laufe des Jahres 1960 zunehmend nervōser. Der Auszug der Bürger aus der DDR schien unaufhaltsam und bedrohte die Funktionsfāhigkeit der eigenen Gesellschaft immer stärker. Die Verluste ${ }_{n}$ schufen einen Teufelskreis von Unzufriedenheit und Wanderlust: Je mehr Men-

79 Zu diesem Fall vgl. Nieske, Republikflucht (2001), S. 283-298.

${ }^{30} \mathrm{Zu}$ diesem Vorgang vgl. Ciesla, „Feindobjekt“ (2005), S. $160 \mathrm{f}$.

81 Zu diesen Vorgāngen vgl. Ciesla, „Feindobjekt" (2005), S. 162.

*2 Befehl Nr. 301/61 vom 8. 7. 1961, BStU ZA, MfS-BdL, Nr. 000705, B1. 1-4.

*s Anweisung Nr. 1/60, 4.5. 1960, BStU ZA, MfS-BdL, Nr. 003499, Bl. 1. 
schen flohen, desto schlimmer wurde es wirtschaftlich - je schlimmer es wurde, desto mehr flüchteten." ${ }^{\text {"st }}$

Auch innerhalb der Staats- und Parteiapparate wurde der Ton Anfang der sechziger Jahre nervöser. ${ }^{85}$ Die einzelnen Abteilungen lieferten zwar noch die typischen Berichte aus einzelnen Bezirken und Betrieben $a b,{ }^{86}$ und alle Gremien setzten ihre üblichen, weitgehend wirkungslosen Aktivitäten fort ${ }^{87}$ Im Hintergrund bereiteten sich die politischen Spitzen aber längst auf eine endgültige Lōsung vor, um die Flucht- und Abwanderungsbewegung zu unterbinden. Dazu traf die SED internationale Vorbereitungen und Absprachen, die schlieBlich in der Nacht vom 12. zum 13. August 1961 in den Mauerbau durch Berlin mündeten. ${ }^{88}$

Mit der GrenzschlieBung im August 1961 erkannte die DDR-Führung an, daB sie gegenüber der Unzufriedenheit eines Großteils der Bevölkerung hilflos war. Gleichzeitig befreite sie sich damit auch von ihrer jahrelangen Machtlosigkeit gegenüber der Fluchtwelle. Wie schon die drei großen Einschnitte gezeigt haben, bewegten sich einige Schritte gegen die Republikflucht sehr nahe an den traditionellen Bereichen der Reise- und Grenzpolitik.

„Auf eine Frage, wie man dieser Abwanderung von Fachkräften entgegenwirkt, erklärte der Kaderleiter, daß sie niemanden festhalten kōnnen, wenn sie nach Westdeutschland wollen. Das Zweckmäßige wäre seines Erachtens, die Grenzen dicht zu machen. ${ }^{\text {"g9 }}$ So wie der Kaderleiter des Magdeburger VEB (Volkseigener Betrieb) Schwermaschinenbau Karl Liebknecht trat eine ganze Reihe von kompromißlosen SED-Mitgliedern schon Mitte der fünfziger Jahre für die vōllige Schließung der westlichen und der Berliner Grenze der DDR ein. Den möglichen Exekutoren dieser rigorosen Maßnahme fiel diese Entscheidung nicht so leicht, da sie internationalen Zwāngen unterlagen, vor allem aber die damit verbundene politische Bankrotterklärung vermeiden wollten. Zum einen sollte die gesellschaftliche Akzeptanz gewonnen werden - auf nichts anderes zielte Ulbrichts Idee vom Überholen des westlichen Konsumniveaus -, zum anderen ging es um den Nachweis des eigenen politischen Geschicks: „Republikfluchten sind kein Naturgesetz, mit diesem Problem muß man fertig werden. ${ }^{40}$

Angesichts der offenen Stadt Berlin war das Ziel nur schwer zu erreichen: Wurde der Reiseverkehr eingeschränkt, stieg der Unmut der Bevōlkerung, gewährte Ost-Berlin in diesem Punkt mehr Freiheiten, so beendeten viele ihren Urlaub im Westen nicht mehr. Das

\footnotetext{
84 Major, Torschlußpanik (2000), S. 227.

8s Vgl. z.B. die Note der DDR-Regierung an Westalliierte gegen BRD-Revanchismus vom 13.6.1961 (SAPMO-BArch DY 30/J IV 2/2/768, Bl. 49); die Äußerungen des PB zum West-Berliner Kirchentag vom 11. 7. 1961 (SAPMO-BArch DY 30/J IV 2/2/775, Bl. 2 f.); BeschluB des PB zur Verstärkung der Auslandspropaganda bzgl. Westberlinfrage vom 25.7.1961 (SAPMO-BArch DY 30/J IV 2/2/779, BI. 141-161).

${ }_{86}$ Vgl. etwa den Bericht des SED-Sekretariats über Republikflucht im Bezirk Halle (SAPMO-BArch DY 30/J IV 2/3-740, Bl. 60-83).

87 Vgl. z.B. PB am 18.10.1960 zu Maßnahmen zur Verbesserung der Verhältnisse an der Westgrenze (SAPMO-BArch DY 30/J IV 2/2/730, Bl. 2); ZKSekr am 4. 11. 1960 zu Maßnahmen zum Stop der Republikflucht von Ärzten und Lehrern (SAPMO-BArch DY 30/J IV 2/3-710, BI. 1 f.); PB setzt am 18. 7. 1961 Arbeitsgruppe zur Bekāmpfung der Republikflucht "mit legalen Mitteln“ ein (SAPMO-BArch DY 30/J IV 2/2/777, Bl. 3).

Zum Mauerbau vgl. Küchenmeister, Mauerbau (2001); Eisenfeld/Engelmann, Mauerbau (2001). Zu verschiedenen Aspekten des Mauerbaus und seiner Vorgeschichte vgl. auch die Beiträge in Hertle/ Jarausch/KleBmann, Mauerbau und Mauerfall (2002): Steininger, Mauerbau (2001).

HA PM am 26. 11. 1955 an ZK der SED (BArch DO 1/11, Nr. 963, B1. 64).

90 Staatssekretär Grünstein am 6.9. 1958, BArch DO 1/11, Nr. 79, Bl. 5.
} 
Dilemma war leicht zu erkennen. So āußerte Maron schon Anfang August 1953, also zu Beginn der liberaleren Ausgabe der Interzonenpässe, die Vermutung, daß ein großer Teil der Reisenden den Interzonenpaß zur Legalisierung der Republikflucht ausnutzt. ${ }^{\text {"9l }}$ Die Maßnahmen gegen die Republikflucht muBten zwar die Androhung von Sanktionen wie Enteignung, Besuchsverbote oder Haft einschlieBen, gleichzeitig wollte sich das Regime aber gegenüber der (noch) verbliebenen Bevölkerung freundlich aufführen und darüber hinaus einige der Geflohenen zurückgewinnen. Mehr als drei Jahre später stellte sich für den inzwischen zum Innenminister avancierten Maron die gleiche Frage: „Es sollen deshalb Vorschläge ausgearbeitet werden, die dazu geeignet sind, die Republikfluchten einzuschränken, auch wenn damit für bestimmte soziale Gruppen oder bestimmte Gebiete Einschränkungen im Interzonenreisewesen herauskommen." Eine Lösung für den Zielkonflikt, daB jede Maßnahme zugleich die eine Richtung bediente, der anderen aber zuwiderlief, hatte er auch nicht: „Diese MaBnahmen dürfen jedoch nicht so sein, daB damit die von der Regierung der DDR proklamierte Freizügigkeit im Reiseverkehr aufgehoben oder für große Bevölkerungsteile stark eingeschränkt wird. Wenn das auch im bestimmten Widerspruch zueinander steht, so muB man zwischen beiden Erfordernissen den richtigen Weg finden. ${ }^{\text {"92 }}$ Ihn zu finden, blieb den nachgeordneten Behördenmitarbeitern überlassen.

Etwa 1952/53 - also zeitgleich mit der Wahrnehmung der problematischen Seiten der massenhaften Auswanderung - begann die DDR-Führung damit, Fachleute aus dem Westen anzuwerben. Den Hintergrund bildete der aus dem Rostocker Polizeibericht von 1952 bereits zitierte Anspruch, ${ }^{93}$ die deutsch-deutsche Migration ,in administrativer wie auch ideologischer Hinsicht ${ }^{“}$ zugunsten der DDR ${ }_{\text {zu lenken }}$. Die ,Feinde' sollten das Land verlassen und kompetente Fachleute ihre Zukunft in der DDR erkennen.9

Um die ,richtigen' Menschen zu gewinnen, initiierte die DDR Werbekampagnen, in denen etwa Ärzte aufgefordert wurden, der im Westen noch verbreiteten Arbeitslosigkeit durch den Umzug in die DDR zu entgehen. ${ }^{95}$ Den Zugezogenen wurde zudem der Neubeginn durch günstige Kredite oder Einrichtungsgegenstände für neue Wohnungen erleichtert. ${ }^{96}$ Angesichts zahlloser bürokratischer Hürden und sicherheitspolitischer Maßnahmen, die den Zuziehenden das berufliche und private Leben erschwerten, verpuffte die positive Wirkung solcher Starthilfen gewöhnlich aber schnell. Recht bald zeichnete

${ }^{91}$ Maron am 7. 8. 1953 an MdI Stoph und Abt. PM (BArch DO 1/11, Nr. 962, Bl. 98f.).

${ }^{92}$ HVDVP, HA PM, VP-Inspekteur Fischer, 13. 3. 1957: Vermerk über zwei Besprechungen bei Minister Maron und bei Genosse GroBmann, BArch DO 1/11, Nr. 964, Bl. 93-98, hier Bl. 93.

93 Vgl. Dok. 13.

94 Zu diesem Themenkomplex vgl. auch Schmelz, Migration und Politik (2002), S. $79 \mathrm{ff}$.

${ }^{95} \mathrm{Vgl}$. BArch DO 1/11, Nr. 961, Bl. $29 \mathrm{f}$.

96 BArch DO 1/11, Nr. 708, Bl. 34; BArch DO 1/11, Nr. 780, Bl. 2 f., 5 ; vgl. auch den Bericht „Die Fluchtbewegung aus Westdeutschland und Westberlin in die Deutsche Demokratische Republik", in dem Überbrückungsgelder durch Stâdte und Gemeinden, die Bereitstellung von ${ }_{n}$ geeignete[m] Wohnraum" sowie günstige Kredite für Möbel und Hausrat erwähnt werden. (BArch DO 1/34, Nr. 23724). Vgl. auch die Anordnung über die finanzielle Hilfe für Personen, die ihren Wohnsitz aus Westdeutschland und Westberlin in das Gebiet der Deutschen Demokratischen Republik oder des demokratischen Sektors von Groß-Berlin verlegen” (Dok. 7) und die ähnlich lautende Anordnung zur „Kreditgewāhrung“, beide vom 29.4. 1954 (ZBl. Nr. 20, 22. 5. 1954, S. 204 ff.). Anfang 1958 wurden die Vergünstigungen wieder eingeschränkt und galten nur noch für erstmalig Zuziehende. Vgl. die entsprechenden Anordnungen vom 24. 2. 1958 (GBl. Nr. 23, 10.4. 1958, S. 306 f.) und vom 28. 4. 1958 (GBl. Nr. 31, 24. 5. 1958, S. 308). Zum EntscheidungsprozeB für diese Einschränkungen vgl. SAPMO-BArch DY 30/J IV 2/2/539, Bl. 5 und SAPMO-BArch DY 30/J IV 2/2/546, Bl. 4. 
sich ab, daß die ehrgeizigen Pläne der SED, hochqualifizierte Fachleute ins Land zu holen, in einem "Desaster" endeten. ${ }^{97}$ Ihren einzigen nennenswerten Erfolg verzeichnete die DDR infolge des Neuen Kurses.98

Die quantitativen Mißerfolge dieser Maßnahmen blieben den Ost-Berliner Parteien und Institutionen nicht verborgen, aber sie fanden aufgrund des unbedingten Primats der Sicherheitspolitik und der allgemeinen Versorgungsprobleme keine Alternativen. So gab es immer wieder Appelle, Menschen aus der Bundesrepublik abzuwerben ${ }^{99}$ und die CDU-Leitung ließ sich noch $1957 \mathrm{zu}$ dem Versuch hinreißen, ausgerechnet geflohene Industrielle und Unternehmer zur Rückkehr in die DDR zu bewegen, ${ }^{100}$ obwohl ein Parteifreund schon 1955 darauf hingewiesen hatte, daB nur wenige Westdeutsche die DDR attraktiver fänden als die Bundesrepublik, solange sie dort „stundenlang nach einem halben Pfund Margarine" anstehen müBten. ${ }^{101}$ Trotz der zuweilen weitreichenden Zugeständnisse ${ }^{102}$ blieben die Erfolge gering. Statt dessen beschlich die Verantwortlichen langsam die Erkenntnis, daB viele Menschen ihre Zuzugs- und Integrationsangebote annahmen, für die diese gar nicht gedacht waren: Spãtestens Ende der fünfziger Jahre gingen daher fast alle mit Flucht und Abwanderung beschãftigten Behörden der DDR dazu über, das Problem der Zuziehenden aus dem Westen in erster Linie unter kriminalistischen und strafrechtlichen Aspekten zu betrachten. So sollten die Zuwanderer immer genauer hinsichtlich ihrer SeBhaftigkeit und ihres Strafregisters überprüft werden ${ }^{103}$ und auch die fi-

97 So Jessen, Akademische Elite (1999), S. 297-301, 424 f., über die Versuche, westliche Wissenschaftler an DDR-Hochschulen zu holen, weshalb solche Kampagnen seit 1953 nicht wiederholt worden seien.

* Allerdings kehrten auch 1953 viele mit einem Vorbehalt zurück; so kamen Mütter und Kinder zurūck. während die Vāter in West-Berlin blieben. Vgl. Maron am 30.4. 1954 an Matern, im ZK der SED (BArch DO 1/11, Nr. 962, Bl. 198).

9 Die Werbung von Bürgern der Bundesrepublik war nur eine der Maßnahmen, die in umgekehrter Richtung als Politik von Kriegstreibern, Spaltern und Imperialisten beschimpft wurde. Obwohl die SF.D sich jede westliche Einmischung in die Angelegenheiten der DDR verbat, schickte sie regelmäßig Kader zu westdeutschen Bundestags- und Landtagswahlen (vgl. z.B. SAPMO-BArch DY 30/J IV 2/2/583, Bl. 2 f.; SAPMO-BArch DY 30/J IV 2/3-35, Bl.11; SAPMO-BArch DY 30/J IV 2/3-98, Bl.6; SAPMO-BArch DY 30/J IV 2/3-175, B1. 8; SAPMO-BArch DY 30/J IV 2/3-193, BI. 1 f.; SAPMO-BArch DY 30/J IV 2/3-184, Bl. 11 f.; SAPMO-BArch DY 30/J IV 2/3-175, Bl. 18), die SED empfing westdeutsche Jugendliche mit Schimpftiraden über die Gründung der Bundeswehr, während sie selbst ihre bewaffneten Organe ausbaute (SAPMO-BArch DY 30/IV 2/2/337, Bl. 49 ff.; BArch DO 1/34, Nr. 21724; Dok. 22) und ließ „Mittelwellensender für Westdeutschland an der Zonengrenze ${ }^{*}$ errichten, während sie den Empfang des westdeutschen Rundfunks kriminalisierte (SAPMO-BArch DY 30/J IV 2/3-67, Bl. 2). Besonders offensichtlich war diese Doppelbödigkeit in ihrer Polemik gegen die westliche Grenz- und Reisepolitik: Wāhrend Ost-Berlin die Grenze zunehmend stärker verriegelte, empörten sich SED und ND immer wieder über den regelrechte[n] Polizeiterror" bewaffneter westlicher Organe „entlang der Interzonengrenze" (SAPMO-BArch DY 30/J IV 2/3-430, BI. 14 f.).

${ }^{100} \mathrm{Zu}$ dem erfolglosen Versuch vgl. den Musterbrief Sefrins vom 1. 7. 1957 und zahlreiche Antwortbriefe (ACDP VI1-011, Nr. A1015).

101 Aus einem Informationsbericht der CDU-Parteileitung vom 15. 12. 1955, zitiert nach Suckut, Frwartung (1993), S. 427.

102 Vgl. z.B. BArch DO 1/11, Nr. 917, Bl. 3, 40; 1956 lud die Regierung auf der ersten Seite des ND selbst straffällige Republikflūchtige zur Rückkehr ein: „Sie können damit rechnen, daB sie mit der gleichen Großzügigkeit behandelt werden, wie die 20000 Verurteilten, die aus der Strafhaft entlassen wurden und die ohne Benachteiligung ihrer friedlichen Arbeit nachgehen kōnnen." (ND Nr. 233 v. 28. 9. 1956, S. 1). 10 V Vl. dazu die Antwort der HA PM auf eine Anfrage vom 25. 1. 1957, welche Gegenmaßnahmen gegen unzuverlässige Rückkehrer und Zuziehende (Arbeitsscheue, Bummelanten, Landstreicher, Kriminelle etc.) getroffen werden kōnnen, die auch eine Liste mit Ablehnungsgründen enthält (BArch DO I/11. Nr. 964, Bl. 19-33; Anfrage: Bl. 17f.). 
nanziellen und materiellen Vergünstigungen wurden drastisch eingeschränkt. ${ }^{104}$ Letzteres geschah auch mit Rūcksicht auf die einheimische Bevōlkerung, die den Zuwanderern überwiegend ablehnend gegenüberstand und ,alle Sonderzahlungen an Migranten aus der Bundesrepublik mißbilligte ${ }^{*} .105$

Gemessen an ihrem empirischen und analytischen Interesse an der Republikflucht widmeten die Organe der DDR den Rūckkehrern und Zuziehenden überdimensional viel Aufmerksamkeit. Die meisten mit der deutsch-deutschen Grenze beschäftigten Mitarbeiter von DDR-Behörden bevorzugten dieses Thema, weil die Zuwanderung der Selbstdarstellung der DDR nicht ganz so drastisch widersprach wie die chronische Westflucht. Außerdem bewegte sich die SED sicherer auf dem Gebiet der Absichtserklärungen und Propaganda, als auf dem der konkreten und am Ergebnis überprüfbaren Politik. So legte das Sekretariat des ZK am 22. Dezember 1952 in seinen ${ }_{n} \mathrm{MaBnahmen}$ gegen die Republikflucht" auch fest, regelmäBig positive Berichte über in die DDR gekommene westdeutsche Arbeitnehmer in der DDR zu veröffentlichen, Betriebsversammlungen einzuberufen und auf Wandzeitungen die positiven und negativen Beispiele hervorzuheben. Da zu den „Hauptursachen" für die

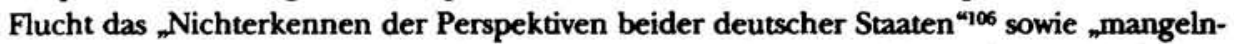
des StaatsbewuBtsein und mangelndes Vertrauen zu den Perspektiven der sozialistischen Entwicklung ${ }^{107}$ zāhlten, sollte das politische Bewußtsein durch Werbung gehoben werden: „Es muß uns noch überzeugender gelingen, die Unbesiegbarkeit des Sozialismus und die Entwicklung in der DDR als Perspektive für ganz Deutschland darzulegen “. 108 Dazu hāngten SED und Freier Deutscher Gewerkschaftsbund (FDGB) in Betrieben Wandzeitungen aus, sollten namhafte Mediziner sich gegen die Flucht ihrer Kollegen ãußern, ${ }^{109}$ lieB die

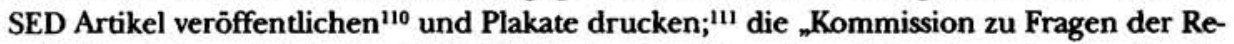
publikflucht" entwickelte im Mai 1956 für das Politbüro einen MaBnahmenkatalog für die "fortlaufend" zu verbessernde Agitation u. a. durch Presse, Radio, DEFA-Wochenschau, Spiel- und Dokumentarfilme, Romane und Hörspiele. ${ }^{112}$ So druckten die Tageszeitungen ${ }^{113}$ und Zeitschriften zahlreiche Artikel ab, die sich in ihrer Intention nicht wesentlich von-

194 Am 25. 6. 1957 entschied sich das PB für eine Einschränkung der Vergünstigungen für Rūckkehrer und Zuziehende: finanzielle Hilfe sollten Erstzuziehende nur dann erhalten, „wenn ihr Verhalten dies rechtfertigt und die Voraussetzungen zur Abtragung des Kredits gegeben sind.“ Regionale Konzentrationen von Rückkehrern und Zuziehenden sollten vermieden werden (SAPMO-BArch DY 30/J IV 2/2/546, Bl. 4).

105 Schmelz, Migration und Politik (2002), S. 287.

106 Ratsvorlage zum Tagesordnungspunkt 4 der Ratssitzung vom 4. 6. 1958 (BArch DO 1/34, Nr. 21725).

107 SAPMO-BArch DY 30/J IV 2/2/775, Bl. 12-98, hier Bl. 49: Sitzung des Politbüros des Zentralkomitees am 11.7. 1961.

I0* BArch DO 1/11, Nr. 558, B1. 78-101: „Die Aufgaben der Volkspolizei im Kampf gegen die Republik-

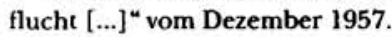

109 SAPMO-BArch DY 30/J IV 2/2/608, Bl. 3 (Sitzung des PB am 2. 9. 1958).

$110 \mathrm{Vgl}$. z.B. die Aufforderung des ZKSekr vom 24.2. 1954 zur ständige[n] Pressearbeit" über Republikflucht: Diskreditierung der Bundesrepublik durch Rückkehrer; Presse- und Rundfunkvertreter sollen „die Lage in den westberliner und westdeutschen Elendslagern studieren und ihre Eindrücke popularisieren." (SAPMO-BArch DY 30/J IV 2/3-420, Bl. 18).

III Allerdings verfügte das ZKSekr am 22.8.1956, zwei vorgelegte Plakate gegen die Republikflucht nicht auszuhāngen, "weil offensichtlich ist, daß sie die gestellte politische Aufgabe nicht erfüllen kỏnnen" (SAPMO-BArch DY 30/J IV 2/3-325, B1. 4).

112 Dok. 16.

"1s Vgl. zum Beispiel die Artikelreihe ,Die uns verraten' in: Volksstimme. Organ der Bezirksieitung KarlMarx-Stadt der Sozialistischen Einheitspartei Deutschlands zwischen dem 3.12.1957 und dem 13.5. 1958 sowie die in Kap. 2.4, S. 40, Anm. 125 zitierten Artikel des ND. 
einander unterschieden, egal ob sie in Satireblāttern, ${ }^{114}$ Frauen- ${ }^{115}$ und Publikumszeitschriften $^{116}$ oder in den Monatsheften der Polizei ${ }^{117}$ erschienen, aber auf das jeweilige Publikum zugeschnitten waren. Überall las man vom Elend in den Flüchtlingslagern, von falschen Versprechungen, von Erpressungen durch westliche Geheimdienste, von der Arbeitslosigkeit und von gescheiterten Flüchtlingen, die nach ihrer Rückkehr reuevoll über ihr Schicksal berichteten und sich für die Wiederaufnahme in der DDR bedankten. Solche Maßnahmen - die beileibe nicht nur gegen Flucht und Abwanderung organisiert wurden - stießen in der Bevōlkerung auf wenig Interesse, ${ }^{118}$ in Einzelfällen führten sie sogar $\mathbf{z u}$ offenem Widerspruch: „Die Abteilungsversammlungen, die bei Republikfluchten innerhalb des Betriebes durchgeführt werden, sind nicht immer befruchtend im Kampf gegen die Republikfluchten. Es kommt immer wieder vor, daß außer dem Parteisekretār, dem Kaderleiter und der AGL [Abteilungsgewerkschaftsleitung] keiner von den Versammelten weiter eine Stellung zur Frage der Republikfluchten einnimmt. Im Gegenteil, aus dem Hintergrund werden öfters Stimmen laut in der Form: ,Warst Du denn schon mal drüben - wenn Du noch nicht drüben warst, dann sei lieber still - kannst uns nicht überzeugen'. Diese Tatsache führt dann dazu, daß die Abteilungsversammlungen formal durchgeführt werden, um lediglich darüber abzustimmen, daß der republikflüchtige Kollege fristlos entlassen und aus dem FDGB ausgeschlossen wird. "${ }^{119}$

Angesichts der geringen Wirksamkeit der Werbung für die DDR, konzentrierten sich deren Organe bald nicht mehr auf die positive Eigenwerbung, sondern verstärkten die Kampagnen gegen den Westen. ${ }^{120}$ Neben Diffamierungen von einzelnen Flüchtlingen ${ }^{121}$ produzierten die unterschiedlichsten Organe eine unendliche Flut von Dokumenten, Zei-

114 Z.B. Satire "Ein ,politischer' Flüchtling“" (Dok. 38); Karikatur, die das Innere eines Flüchtlingslagers darstellt mit der Unterschrift: „,An wen schreibst Du jetzt ein Gesuch, an Adenauer oder Reuter?" ,An die DDR. Daß wir wieder zurückwollen...” “, in: „Frischer Wind“, 4. Februarheft 1953, S. 5.

113 "Flucht und Heimkehr. Eine wahre Begebenheit", in: Die Frau von heute, 20. 7. 1956. S. 4 f.; „Der lev: te Ausweg eines Republikflüchtigen: Der Strick“. in: ebd., 20. 2. 1961, S. 20; „Eine Frau kehrte zurück" (Dok. 39).

116 „Wenn der Groschen fallt...", Berichte über Rückkehrer in: Neue Berliner Illustrierte, 4. Aprilheft, S. $2 \mathrm{f}$. 117 "Die Flucht in die ,freie Welt'“, Bericht über die Republikflucht von Volkspolizisten, die trotz dieses schweren Verbrechens“ lieber zurūckkommen wollen, statt in der Bundesrepublik leben zu mūsse'n, in: Der Kämpfer, 28. 1. 1956, S. 2; „Für einen Judaslohn die DDR verraten“", Bericht über einen desertierten Volkspolizisten, der wegen seiner aussichtslosen Lage in der Bundesrepublik in dic DDR zurückkehrt. obwohl dort das Gefangnis auf ihn wartet, in: ebd., 26. 5. 1956, S. 4.

I" Bei dem Versuch des Volkspolizeikreisamtleiters, im Dederon-Werk mit den Akademikern über die verhinderte Republikflucht eines promovierten Chemikers und seiner Frau zu sprechen, gab „die âltere Intelligenz [...] dazu nur sehr ausweichende Stellungnahmen ab, wãhrend die junge Intelligenz sich überhaupt nicht dazu ãußerte." (SPK, Chemiekaderkommission, am 28. 7. 1960, BArch DO 1/34, Nr. 21725).

119 Ähnliches wird aus der Universitātsklinik Jena berichtet: „Die Bemühungen der Klinikverwaltung, Professoren und leitende Ärzte zur Unterstūtzung im Kampf gegen die Republikfluchten zu gewinnen. verliefen bis jetzt ergebnislos." Beide Fälle aus einem Brief Seiferts vom 6. 7.1956 an das ZK (Dok. 17).

${ }_{120}$ Liste von verschiedenen Artikeln zur Republikflucht, die zeigt, daß sich das Engagement gegen die Republikflucht vor allem auf Propaganda gegen den Westen konzentrierte, SAPMO-BArch DY 30/ IV 2/13/395, Bl. 153 f. Eine Liste vom 29.11.1957 der verschiedenen DEFA-Filme gegen die Republikflucht in: MdI, HA Innere Angelegenheiten, Abt. I, am 16.1.1958 an 14 Bezirkc und Magistrat von (iroßBerlin, Abt. Innere Angelegenheiten (BArch DO 1/34, Nr. 21725).

121 Immer wieder wurde dabei das „mangelnde[] Bewußtsein dieser Menschen " hervorgehoben (BArch DO 1/11, Nr. 966, Bl. 226; BArch DO 1/11, Nr. 966, Bl. 97; BArch DO 1/11, Nr. 79, Bl. 159, 163), konkrete Anschuldigungen gegen einzelne Auswanderer blieben aber sehr selten. Vgl. u.a. Aruikelserie Die uns verraten ${ }^{\prime \prime}$ in der Volksstimme; Flugblatt „Zerfetzt das Lügengespinst um die .Republikflucht “" von 1953 
tungsartikeln, Radiosendungen und persōnlichen Berichten „über die krasse Unfreiheit in Westdeutschland, über die wachsende Arbeitslosigkeit und den sinkenden Lebensstandard", ${ }^{122}$ die immer wieder mit individuellen Zeugenberichten angereichert wurden. In Nauen verteilte die SED-Kreisleitung 1953 Flugblātter mit einem „Hilfeschrei aus Westdeutschland“" In einem Brief klagte ein junges Paar aus Nauen über seine Arbeit unter erbärmlichen Bedingungen auf einem Bauernhof bei Heidelberg und bat um Möglichkeiten zur Rückkehr in die DDR. Noch deutlicher als der Bericht war die SchluBfolgerung der Kreisleitung: „Schenkt dem betrügerischen Geschnatter der RIAS-Enten kein Gehör. Helft mit, das Ziel und die Politik unserer Regierung, die Einheit Deutschlands, sowie den neuen Kurs zu verwirklichen. Verstärkt den Briefverkehr nach Westdeutschland. Fordert Verwandte und Bekannte, soweit sie republikflūchtig geworden sind, auf, in ihre Heimat zurückzukehren. ${ }^{-123} \mathrm{Zu}$ den stereotypen Vorwürfen an die als reaktionär, kriegstreiberisch und NSfreundlich apostrophierte Bundesrepublik gesellten sich die Schilderungen vom sozialen Elend der Arbeiter und Arbeitslosen, die die SED mit zahlreichen Details und Einzelfalldarstellungen von hochqualifizierten Zuziehenden und Rückkehrern ergänzen lassen wollte. Eine Folge dieses Bestrebens waren Rūckkehrer, die unglaubliche Geschichten über die Zustände in Westdeutschland erzählten, mit denen sie wohl in erster Linie die Erwartungen der Interviewer befriedigen wollten. Solche Erzählungen stießen bisweilen selbst bei den Sicherheitsorganen auf Skepsis. So berichtete ein aus Köln in die DDR zurückgekehrtes Ehepaar von Belästigungen durch Besatzungssoldaten, von Jugendlichen, die sich zu großen Gruppen zusammenrotteten, und davon, „daB man selbst am Tage auf der Straße nicht sicher wäre, weil kriminelle Elemente beim grōBten Verkehr Schaufenster einschlagen oder mit Pistolen zerschießen “. Selbst dem Polizist, der den Bericht aufnahm, schienen diese Schilderungen netwas übertrieben“; trotzdem kam er zu dem $\mathrm{SchluB,}$ daß sie „keine Erfindungen sind, sondern daß ihnen diese Zustānde die Veranlassung gaben, in die DDR zurückzukehren". ${ }^{124}$

Inwiefern solche Geschichten auch bei der Bevölkerung Glauben fanden, ist schwer zu bestimmen. Der Exodus ließ auf jeden Fall nie nennenswert nach, und als die SED-Führung ihre Macht wieder gefestigt hatte, reduzierte sich das Entgegenkommen auf eine jeweils individuell angepaßte Privilegierung einzelner Menschen, deren Flucht verhindert werden sollte. ${ }^{125}$ Den verantwortlichen Organen Ost-Berlins war bewußt, daß eine diffe-

mit der Nennung von Namen und Fluchtschädigung (in: SAPMO-BArch DY 30/IV 2/13/394, Bl. 98f.; weitere Flugblätter gegen Republikflucht und für Rūckkehrer und Zuziehende in: SAPMO-BArch DY $30 /$ IV $2 / 13 / 394$, Bl. 406 ff.).

122 Anweisung des ZKSekr vom 22. 12. 1952 (SAPMO-BArch DY 30/J IV 2/3-35, B1. 49).

123 SAPMO-BArch DY 30/IV 2/13/394, Bl. 406 ff., hier Bl. 406.

124 Dok. 37.

125 Solche individuellen Privilegierungen konnten sich jedoch auch als Bumerang erweisen. Ein hochbezahlter Facharzt nutzte seine fast unbeschränkte Möglichkeit zu Westreisen dazu aus, vor seiner Flucht die gesamte Einrichtung seines Hauses nach Westdeutschland zu schaffen (Einzelinformation über die Republikflucht eines Lungenspezialarztes, 28. 4. 1961, BStU ZA, MfS-ZAIG, Nr. 408, Bl. 1-7). Zur Privilegierung vgl. auch Kap. 4; zu Medizinern vgl. Jessen, Akademische Elite (1999), S. 188, 218, und das Kommuniqué des PB vom 19.10.1960 über ${ }_{n}$ MaBnahmen zur weiteren Entwicklung des Gesundheitswesens und zur Förderung der Arbeit der medizinischen Intelligenz ${ }^{*}$ (ND Nr. 351 v. 20.12. 1960, S. 1 f.) sowie āhnliche Versprechungen an Lehrer (Deutsche Lehrerzeitung vom 9. 12. 1960, S. 1 f.; zu taktischen Konzessionen der SED vgl. auch Jänicke, Der dritte Weg [1964], S. 168); zu Einzelverträgen für erfahrene Ingenieure vgl. Augustine, Frustrierte Technokraten (1996), S. 67. 
renziertere Behandlung ihrer Bürger das beste Mittel zur Verhinderung von Unzufriedenheit und damit auch von Republikfluchten war: „Das Hauptkettenglied ist die Verbesserung der Arbeit mit den Menschen und ihre Einbeziehung in die Leitung und Lenkung des Staates. ${ }^{126}$ Problematisch war insbesondere das Selbstverstāndnis der SED, die sich selbst zur Inkarnation des Willens der Bevōlkerungsmehrheit erklärte. ${ }^{127}$ Daher fiel es ihr - abgesehen von der dramatischen Ausnahmesituation im Sommer 1953 - schwer, die eigenen Maßnahmen als Ursache für die massenhafte Abwanderung zu erkennen, galt ihr doch der Umbau der Gesellschaft in einer diffusen Mischung aus politischem Idealismus und dogmatischer kommunistischer Parteiideologie ais Weg zum Wohl der Mehrheitsgesellschaft. Selbst solche politische Initiativen, mit denen die Flucht besonders verstärkt wurde, dienten angeblich nur der Erhöhung des Lebensstandards in der DDR: Mit den Kollektivierungen in der Landwirtschaft sollten die Produktion und das Lebensmittelangebot erhöht werden, mit den Enteignungen in Handel und Industrie wurden Leistungsverbesserungen und der Abbau von angeblich personalintensiven Überkapazitāten versprochen, die Entscheidung für die Konzentration auf den schwerindustriellen Sektor basierte auf dem Wunsch, die gesamte DDR-Wirtschaft auf robuste Füße zu stellen. Dies galt nicht nur für die Wirtschaftspolitik, sondern für jede Initiative der SED: Selbst der erschwerte Zugang für Akademikerkinder zum Hochschulstudium galt als Privilegierung der Bevōlkerungsmehrheit und die restriktive Kunst- und Kulturpolitik als Annäherung an den Mehrheitsgeschmack. Angesichts dieser Selbstinterpretation erschien die Durchsetzung von politischen Liberalisierungen nicht nur aufgrund des politischen Eigengewichts der Partei- und Verwaltungsapparate in den Kreisen und Bezirken schwer, sondern mehr noch aufgrund der in ihnen mehrheitlich vertretenen Auffassung, daß ein möglichst schneller Weg zum Sozialismus die sicherste Garantie nicht nur für die eigene Macht, sondern auch für die beste aller denkbaren Gesellschaften war.

Da die allgemeinen Privilegierungen nicht ausreichten und die Grenz- und Reisepolitik nicht liberalisiert wurde, bemūhte sich Ost-Berlin wiederholt um Trostpflaster, etwa die Verbesserung der Tourismusmöglichkeiten in den sozialistischen Bruderstaaten, vor allem der CSR und Polen. ${ }^{128}$ Im Bereich der Grenz- und Reisepolitik blieben konkrete Liberalisierungen aber - wiederum abgesehen vom Sommer 1953 - in nennenswertem Umfang aus. Angesichts der weitgehend ungebrochenen Flucht und Auswanderung in den fünfziger Jahren und ihrer demographischen Folgen verwundert es, daß die SED statt dessen immer wieder politische Verschärfungen verfügte, die die Republikfluchten zeitweise noch stärker ansteigen ließen. Beispielhaft zeigt sich dies an der Einführung einer neuen Assistentenverordnung für die Universitāten 1957/58: „Es ist aus der Rūckschau nur schwer nachzuvollziehen, [...] daß die verantwortlichen Entscheidungsträger diese naheliegende Konsequenz ihrer Politik offenbar kaum vorhergesehen haben. Es hātte nicht viel Phantasie dazugehört, sich die Reaktion junger Wissenschaftler vorzustellen, die ihre berufliche Zukunft durch politische Pressionen bedroht sahen und denen zugleich eine

${ }^{126}$ So Seifert in den SchluBfolgerungen eines Berichts vom 9.3.1961 an MfS Mielke (BArch DO 1/11, Nr. 967, Bl. 65-69, hier Bl. 66).

127 Genau dies gab ein Arzt in seinem Abschiedsbrief als Hauptgrund für seine Republikflucht an: .Was für mich in der DDR immer unertuäglicher wurde, war die Anmaßung des Staates, für seine Bürger zu ,denken " und das einmal festgelegte Dogma als allgemein verbindlich zu erklären." (Dok. 29).

${ }^{12 k}$ Vgl. BeschluB des ZKSekr am 20.6. 1956 (SAPMO-BArch DY 30/J IV 2/3-517, BI. 4 f.). 
attraktive Alternative zugänglich war, wenn sie sich nur eine Fahrkarte der Berliner S-Bahn kauften. ${ }^{\text {} 129}$

Statt den Reiseverkehr über die deutsch-deutsche Grenze zu liberalisieren, wurden die Restriktionen in den fünfziger Jahren noch erweitert, indem die Züge nach Berlin durch Zugbegleitkommandos kontrolliert wurden und die Transportpolizei den Ring um Berlin bewachte, damit sich niemand unerlaubt der offenen Grenzstadt nāhern konnte. ${ }^{130} \mathrm{Ne}$ ben dem Verbot, die DDR ohne offizielle Erlaubnis der Volkspolizei zu verlassen, richtete die Polizei noch verschiedene Systeme von Karteikarten, Registrierungen und Sichtvermerken ein, die einzelnen Fluchtversuchen vorbeugen sollten. So sei jede verhinderte Flucht auf der Kreismelde- und Meldestellenkartei „in der Spalte Akten- und Strafhinweise" zu vermerken, wodurch die Polizei über etwaige Umzüge der betreffenden Personen informiert wurde, ${ }^{131}$ die Hauptabteilung PM führte eine „Sperrkartei für Aufenthaltsgenehmigungen ${ }^{{ }_{132}}$ und die Volkspolizeiämter führten namentliche Listen von Republikflüchtigen. ${ }^{135}$ Darüber hinaus muBte beim Kauf von Fotoapparaten und anderen hochwertigen optischen Gerāten oder beim Abheben hoher Geldsummen von Sparkonten der Personalausweis vorgelegt werden: Die Polizei notierte dies in ihren Karteien und strengte zuweilen stārkere Überwachungen der betroffenen Personen an, da sich viele Flüchtlinge durch ihre Ersparnisse oder durch die in der DDR preiswerten und im Westen gut verkāuflichen Waren den Neuanfang erleichtern wollten. ${ }^{134}$ Nur selten wurde von Erfolgen dieser MaBnahmen berichtet. So lobte die Hauptabteilung PM im August 1954 zwar die Republikfluchtkarteien bei den Volkpolizeikreisämtern als gut geführt, mußte aber schon kurz darauf feststellen, ${ }_{\text {daB }}$ die Republikfluchtkartei [im Volkspolizeikreisamt Gotha] nicht in einem gut auswertbaren Zustand ist. ${ }^{135}$ Auch sonst wiesen viele Behördenmitarbeiter darauf hin, daB sie die Karteisysteme aufgrund ihrer Arbeitsūberlastung nicht auf einem aktuellem Stand halten konnten und da $\mathrm{B}$ viele Registrierungen dadurch wirkungslos blieben, ${ }^{136}$ zumal die Behörden noch zahlreiche andere administrative und statistische

129 Jessen, Akademische Elite (1999), S. 92.

130 Vgl. z.B. BArch DO 1/11, Nr.965, Bl. 141 (19. 12. 1958); BArch DO 1/11, Nr. 966, Bl. 21 (5. 3. 1959).

19. HVDVP am 21. 10. 1955: Anweisung an die VPKÄ über BDVP (BArch DO 1/11, Nr. 963, B1. 59).

1s2 Bericht Seiferts aus AnlaB der Republikflucht des technischen Leiters und des Direktors der VEB Elektromotorenwerk Wernigerode am 6.3. 1957 an das ZK der SED, das MfS, das ZK für staatliche Kontrolle und die HA PM (BArch DO 1/11, Nr. 964, Bl. 91).

138 HA PM am 7.2. 1953 (BArch DO 1/11, Nr. 962, Bl. 16).

134 Das PB bestãtigte am 21.12.1954 „Maßnahmen gegen Schieber und Spekulanten in Berlin“" u.a. mehr Kontrollen, größere Anforderungen an die Buchführung von Privatunternehmen (u.a. bzgl. innerdeutschen Zahlungsverkehrs), Einschränkung des Einkaufs in Ost-Berlin, Verschärfung der Kontrollen um Berlin, Verbesserung des ostdeutschen Warensortiments (SAPMO-BArch DY 30/IV 2/2/397, Bl. 5, 36-40); Forderungen nach besserer Kontrolle von Westreisenden bzgl. der Mitnahme von optschen Gerāten (21. 10.1955: BArch DO 1/11, Nr.637, Bl.41); nach BArch DO 1/11, Nr. 780, Bl.5 (27. 4. 1956) wurden auch Sparkassenkredite auf der Karteikarte der Abt. PM notiert: Die Karten mūssen ziemlich groß gewesen sein.

iss BArch DO 1/11, Nr. 962, Bl. 208-211.

136 Seifert, HA K, kritisierte am 22. 12. 1956, daß die „Sperrkartei für Westberliner Bürger“ mit 55000 Einträgen bei den Untersuchungsorganen nicht bekannt sei und nicht genutzt werde (BArch DO 1/11, Nr. 780, Bl. 22); vgl. auch den Hinweis der HA PM am 1.7.1957 an verschiedene BDVP: Mehrere hundert unbearbeitete Sperrvermerke in den Aufnahmestellen seien noch nicht in die Sperrkartei eingearbeitet: ganz offensichtich funktionierten die zahlreichen Karteien zur Überprüfung und Kontrolle der Grenzwanderer nur unzureichend (BArch DO 1/11, Nr. 964, Bl. 128). 
Erfassungen vornahmen. Viele Maßnahmen, etwa die genaue Registrierung der bei Besuchsreisen mitgeführten hochwertigen Industrieerzeugnisse, verhinderten keine Fluchten, sondern führten erst dazu.

Bei fast allen MaBnahmen gegen die illegale Auswanderung machten die Behörden der DDR die gleiche Erfahrung der Unwirksamkeit. Da sich der Massenexodus aber zu einer existentiellen Bedrohung entwickelte, bemühten sich verschiedene Institutionen um eine Zusammenarbeit. Schon Anfang der fünfziger Jahre entstanden auf zentraler und regionaler Ebene die ersten Kommissionen mit Mitgliedern verschiedener Abteilungen der staatlichen Verwaltung und der SED. ${ }^{137}$ Ihre Aktivitäten beschränkten sich aber auf Analysen, politische Absichtserklärungen und einzelne Versuche, die Abwanderung durch Gespräche mit den Fluchtwilligen oder die Behebung konkreter Mißstände in einzelnen Betrieben, Städten oder Behōrden zu verhindern. ${ }^{138}$ Die entscheidende Instanz blieb während der gesamten Zeit bis zum Mauerbau die Polizei, besonders deren Hauptabteilung $\mathrm{PaB}$ - und Meldewesen, die sich vor allem Mitte der fünfziger Jahre über das mangelhafte Interesse der verschiedenen Behörden und Institutionen der DDR an den Fluchten als ${ }_{n}$ Ressortgeist" zu beklagen begann. Sie forderte zunehmend hāufiger eine Popularisierung des Kampfes gegen die Republikflucht. Dabei ging es nicht mehr nur um Kommissionen, sondern um den Versuch, die Flucht zu einem Thema zu erklären, das in sämtlichen Bereichen der Politik berücksichtigt werden mußte. Dazu gab es zahlreiche unterstützende Erklärungen, aber die Zusammenarbeit funktionierte trotzdem nicht, zumal keine der betroffenen Institutionen konkrete Handlungsmöglichkeiten angesichts der Fluchtgründe hatte. Denn diese bezogen sich nur teilweise auf konkrete Probleme, hãufiger jedoch auf die allgemeinen Arbeits- und Lebensbedingungen in der DDR.

Ganz offensichtlich hielt die Politik von SED und DDR-Regierung gegen die illegale Auswanderung keine Überraschungen bereit. Die Erfolglosigkeit der regierungsamtlichen Mittel ist fast so bekannt wie ihr Ende, der Mauerbau. Die verschiedenen politischen Maßnahmen, die speziell gegen die Republikflucht gerichtet waren, hatten - abgesehen von der Verschārfung der Reise- und Grenzpolitik Ende 1957 - keinen bedeutenden Einfluß auf den Auswanderungswillen der Bevōlkerung. Wie die Verantwortlichen wiederholt beklagten, hatten der Entzug von Reisegenehmigungen oder Personalausweisen oder die Schließung der Westgrenze der DDR keine nennenswerte Eindämmung zur Folge. Wichtiger war, mit welcher Geschwindigkeit und mit welchem Rigorismus die SED, ihre' Gesellschaft auf den Weg zum Sozialismus schickte.

Zahlreiche Hinweise belegen, daß sich die verantwortlichen Funktionāre keine Illusionen über die Wirkung ihrer Politik machten. So hielt das Protokoll einer Hauptabteilungsleiterbesprechung der HVDVP vom 13. Juni 1959, auf der über die Zunahme von Desertionen in den Reihen der Volkspolizei gerätselt wurde, fest: „Switalla brachte

\footnotetext{
137 Das ZK hatte am 22. 12. 1952 noch die Einrichtung von Kreiskommissionen gegen die Republikflucht abgelehnt (SAPMO-BArch DY 30/J IV 2/3 A-334); Maron weist am 26.3. 1953 alle Chefs der BDVP an, sich wōchentlich mit dem Leiter der HA PM über die Statistiken zur Republikflucht zu verstāndigen

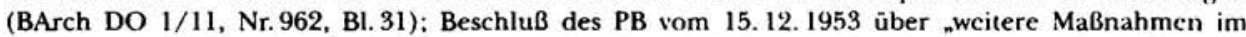
Kampf gegen die Republikflucht" verlangt v.a. eine Intensivierung des Berichtswesens, mehr Aufklärung, mehr ${ }_{n}$ Wachsamkeit" und regelmäßige ressortübergreifende Besprechungen: recht allgemeine Forderungen, die auf kein spezifisches Wissen, sondern nur auf das entstandene Problembewußtsein deuten (SAPMO-BArch DY 30/IV 2/2/337, Bl. 7 f., 49-52).
}

is8 Vgl. z.B. BArch DO 1/11, Nr. 964, Bl. 213-222, hier Bl. 214-218. 
zum Ausdruck, daß durch die Erarbeitung einer Weisung nichts an den Desertionen geān-

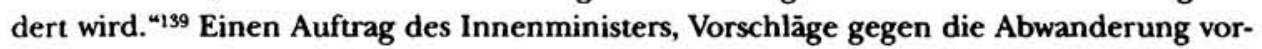
zulegen, beantwortete die Spitze der Volkspolizei im September 1955 mit dem Hinweis, $\mathrm{da} B$ nach eingehender Prüfung [...] keine wirksamen Methoden vorgeschlagen werden kōnnen. ${ }^{140}$ Auf die gleiche Anfrage lieferte die Hauptabteilung PM zwar einige konkrete Vorschläge wie die Wiedereinführung der Genehmigungspflicht für Verzüge in den Westen und bessere Kontrollen an den Sektorengrenzen. Aber auch sie konnte ihre Einsicht in das unkontrollierbare Verhalten der Betroffenen nicht verbergen: „Es darf jedoch hierbei nicht unerwähnt bleiben, daß dieses Verfahren zu einer Erhöhung der Zahlen über Republikfluchten fūhren kann. ${ }^{\text {"141 }}$ Diese Einschātzung kann stellvertretend für praktisch alle gegen die "Republikflucht" gerichteten restriktiven und repressiven Schritte des SED-Regimes bis zum Mauerbau stehen, die in erster Linie dazu beitrugen, daß immer mehr Bürger die DDR verließen.

\footnotetext{
139 BArch DO 1/11, Nr. 93, B1. 44.

140 BArch DO 1/11, Nr. 963, Bl. 45.

141 BArch DO 1/11, Nr. 963, Bl. 46 f. am 31.8. 1955 an Grünstein.
} 
